\title{
A dual-porosity model for the study of chemical effects on the swelling behaviour of MX-80 bentonite
}

\author{
Zhenze $\mathrm{Li}^{1} \cdot$ Grant $\mathrm{Su}^{2} \cdot$ Quinn Zheng ${ }^{2} \cdot$ Thanh Son Nguyen $^{2}$ (1)
}

Received: 13 September 2018 / Accepted: 3 January 2019/Published online: 9 February 2019

(C) The Author(s) 2019

\begin{abstract}
Significant chemical influence on the swelling potential of MX-80 bentonite was observed during swelling tests where specimens were hydrated with highly concentrated brine. The maximum swelling pressure for specimens hydrated with brine was about $30 \%$ of the maximum swelling pressure for the same specimens hydrated with de-ionized water. The maximum swelling pressure was attained within tens of hours of brine infiltration and further decreased by half within a year. A fully coupled hydro-mechanical-chemical (HMC) dual-porosity model is proposed in this paper to interpret the swelling behaviour of MX-80 when infiltrated with brine. The dependence of hydraulic and mechanical properties on such factors as porosity, salinity and water content was investigated. A nonlinear elastic constitutive model was proposed to correlate the swelling pressure with the variation in the microporosity. The chemical effects on the mechanical behaviour were coupled at the micropore level. A number of relationships have been developed for MX-80, i.e. micropore permeability as a function of void ratio, water retention characteristics of micropores and macropores, micropore dependence on water content and the diffusion coefficients of the two types of pore structure. The proposed model was successful in reproducing both quantitatively and qualitatively the experimental results from two sets of infiltration experiments on compacted MX-80 bentonite.
\end{abstract}

Keywords Bentonite $\cdot$ Brine $\cdot$ Coupled processes $\cdot$ Dual porosity $\cdot$ Salinity $\cdot$ Swelling

\section{Introduction}

Bentonite has been widely considered as seal materials in nuclear waste disposal facilities [1, 13, 15, 43, 44, 53]. Bentonite is primarily composed of montmorillonite minerals. Montmorillonite is characterized with high specific surface area, high swelling potential and a strong tendency to bound water. These characteristics could ensure a very low permeability and high sealing capacity of the bentonite when wetted. Deep geological disposal is being considered in Canada and many other countries for the long-term management of nuclear waste. Deep geological repositories (DGR) for nuclear waste rely on a system of engineered and natural barriers to contain and isolate the waste.

Thanh Son Nguyen

son.nguyen@canada.ca

Geoenvironment Consulting, Ottawa, Canada

2 Canadian Nuclear Safety Commission, Ottawa, Canada
Bentonite-based buffer and seal engineered barrier systems (EBS) are major components of this multi-barrier system. Once emplaced between the waste containers and the host rock, the swelling potential of the bentonite upon saturation with porewater from the host rock is relied on in order to seal gaps and fissures that may exist in the EBS itself and/ or the surrounding host rock in the vicinity of the waste emplacement areas. The chemical characteristics of the pore fluid, i.e. $\mathrm{pH}$, salinity, cation types, have been shown to affect the swelling behaviour of the bentonite [13, 21, 32, 49]. In Canada, the porewater in deep geological formations is characterized by high salinity. For example, the total dissolved solids (TDS) of the porewater at the Bruce site, Ontario, where a DGR for low- and intermediate-level wastes is being proposed, are up to $450 \mathrm{~g} / \mathrm{L}$ at depths of more than five hundred metres. The highly concentrated brine in the host rock would seep into the EBS, triggering complex hydraulic $(\mathrm{H})$-mechanical (M)-chemical (C) processes that could affect the swelling potential of the bentonite. These HMC processes are 
coupled and are far more complex than the swelling behaviour of bentonite infiltrated with de-ionized (DI) water. Herbert et al. [18] found that brine with elevated salt concentration in contact with MX-80 bentonite can decrease its swelling pressure to a steady-state value that might take years to be reached. Swelling pressure tests were conducted at Queen's University, Canada, in collaboration with the CNSC [42]. The results showed that the swelling pressure of MX-80 bentonite hydrated with DI water reached a plateau in a monotonous manner after approximately 1 month. On the other hand, for the same specimens hydrated with brine, the swelling pressure increased to a maximum value within tens of hours but reduced slowly to an equilibrium state after approximately 1 year. The final values of the swelling pressure of specimens hydrated with brine are approximately one order of magnitude smaller compared to the DI case. In order to interpret the observed chemical effects on the swelling behaviour of bentonite, the authors have developed in this paper a fully coupled HMC model that takes into account the dual-porosity structure of the bentonite. Although most of the assumptions used in this work might be applicable to other types of bentonite, the focus is on MX-80, a sodium bentonite.

Hydraulic-mechanical (HM)- or thermal-hydraulicmechanical (THM)-coupled models incorporating dualporosity structures have been developed and successfully validated against experimental observations in a number of pioneering studies [3, 12, 16, 17, 19, 37, 46, 47, 50, 55]. Momentum and mass conservation equations for each pore structure are required for the simulation of water flow and vapour transport processes [37]. Dual-porosity-based hydraulic flow and chemical transport models were reported with respect to unsaturated bentonite soils [31, 33, 41, 54]. Recently, a HMC-coupled dual-porosity model was developed by Musso et al. [34] to address the volume change of expansive soil under cycling of chemical permeation. This approach, although only addressing the fully saturated situation, provides an excellent framework to interpret the chemical influences on the swelling behaviour of bentonite [8]. In the present study, the authors developed a HMC-coupled model taking into account the dual-porosity structure of bentonite. The model was based on the dual-porosity HMC-coupled model from Musso et al. [33], but it was extended to address a full spectrum of hydraulic flow in both unsaturated and saturated states. Two types of pore structures were considered: the micropores within the clay aggregates and the macropores between those aggregates. The model considers porewater flow and solute transport in both pore structures and hydraulic and chemical exchange between the two structures through a semi-permeable membrane. This paper is structured as follows: (1) characterization of hydraulic and transport properties of bentonite; (2) derivation of governing HMC equations; (3) development of finite element (FE) models; and (4) mathematical simulation of swelling tests.

\subsection{Characterization of hydraulic and transport properties of bentonite}

\subsubsection{Double-porosity in bentonite}

The microstructure of bentonite has been the focus of many porosimetric and microscopic studies [2, 9, 30, 31, 34, 45]. An illustration of the bentonite microstructure is shown in Fig. 1. The fundamental structural units are the clay platelets or layers, separated by several layers of water molecules and assembled in stacks of 2-3 platelets at full saturation to about 300 platelets at high suctions [48]. The stacks are assembled together in aggregates. From the above microstructural organization, bentonite could conceivably be characterized by three types of pores: the nanopores (at $\mathrm{nm}$ scale) that exist between the clay platelets within a stack; the micropores (in the size range of $0.01-2 \mu \mathrm{m}$ ) between the clay stacks within the aggregate; and the macropores (in the size range of $2-300 \mu \mathrm{m}$ ) that exist between the clay aggregates and other macrograins such as quartz grains.

When water is added to an unsaturated bentonite sample, it infiltrates first into the macropores and then into the micropores and nanopores, resulting in an expansion of the aggregate. This process is involved with a subdivision of the stacks, as well as an increase in the thickness of the diffuse double layer (DDL) [48]. The DDL is generally in the scale of tens of $\mathrm{nm}$ to a few micrometres. The proportion of macropores in the size range of $2-300 \mu \mathrm{m}$ reduces significantly, while micropores in the size range of $0.01-2 \mu \mathrm{m}$ increase in a wetting cycle with DI water. Manca et al. [29] studied the microstructural evolution of bentonite and noticed a steady and quasi-linear increase in micropore volume with decreasing suction in the wetting path. Under confined conditions, the tendency for the aggregate to expand results in the development of a swelling pressure.

Concentrated polyvalent cations in infiltrating waters have been found to decrease the swelling potential of montmorillonite due to a reduction of interlayer expansion, thinner bound water, flocculation of fine minerals and contraction of aggregates [20]. This effect further contributes to the formation of macropores even when the soil is saturated, as evidenced by elevated hydraulic conductivity [20, 29]. Melkior et al. [30] studied the microstructure of various types of bentonite and found that a gel phase in the material governs the pore structure. A homogeneous gel structure is developed in low salinity (typically $\mathrm{NaCl}$, 


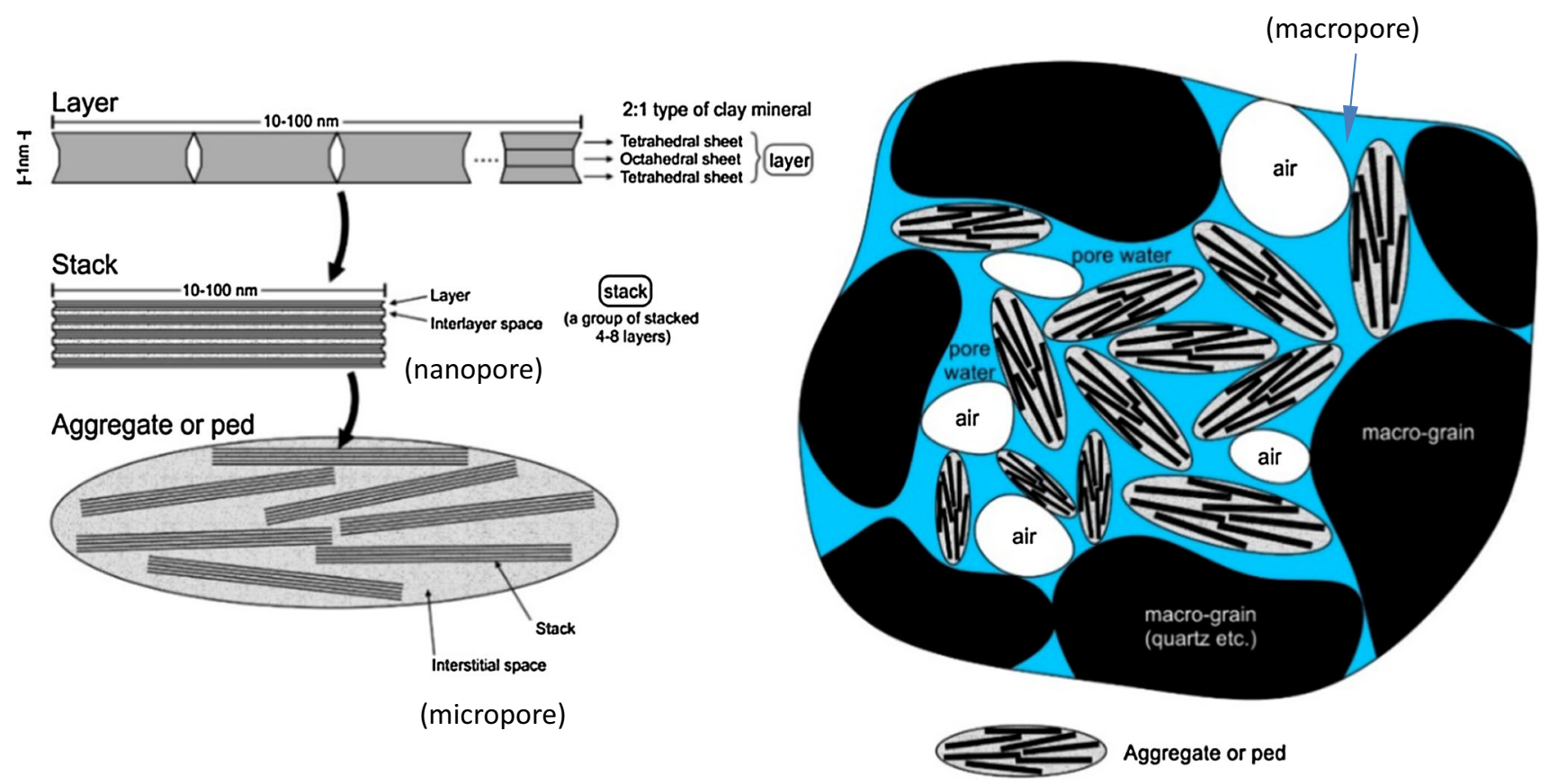

Fig. 1 Illustration of the microstructure of bentonite (from [36])

$10^{-3} \mathrm{M}$ ), showing an isotropic network of clay stacks with 5-10 clay layers. In a concentrated solution $(\mathrm{NaCl}$, $10^{-1} \mathrm{M}$ ), a heterogeneous structure consisting of thicker mineral stacks (40-60 clay layers) is observed. It is shown that increased salinity results in thicker stacks of mineral layers and a closer, denser pack of clay aggregates, which can be illustrated by Fig. 2b, where brine causes the macropore fraction to increase compared to DI water. The simultaneous transport of water and solute in the double structures takes place in such a manner that water moves faster than solute in the micropore and causes the aggregate to expand in the early stage; the solute gradually migrates into the micropore at a later stage and causes the aggregate to shrink to an equilibrium state. This is illustrated in Fig. 2c. The chemical influence on the dynamics of the double structures appears to be somewhat reversible, as leaching of salts from porous media can cause enhanced dispersion and deflocculation in clay slurry [24], which turns out to enhance its swelling potential $[32,34]$.

The mathematical model that is described in this paper is based on the multiple porosity concept as previously discussed. We did not take into account the nanopore and only consider the micropore structure within an aggregate and the macropore structure between the aggregates. This simplification seems to be sufficient in order to explain the main phenomena associated with the swelling of compacted bentonite [17]. Microstructural morphological studies on bentonite under wetting paths indicate a gradual reduction of the macropores and steady cumulative growth in the abundance of micropores [29]. As shown in Fig. 2c,

when full saturation occurs with DI water, the macropores would practically disappear. However, when the bentonite is saturated with brine, the reduction of macropores is much less pronounced with increasing salinity in the pore fluid, as demonstrated in Fig. 2a, b.

\subsection{Hydraulic conductivity of a dual-porosity medium infiltrated with brine}

Assuming that Darcy's law is applicable, porewater flow in a dual-porosity medium depends on the hydraulic conductivity of the bulk medium, which is a function of the hydraulic conductivity associated with each pore type. In a dual-porosity medium, the effective saturated hydraulic conductivity $\left(k_{\text {eff }}\right)$ representative of the overall medium could be expressed as the arithmetic mean of the respective components associated with each porosity type, assuming that flow takes place in parallel in each porosity type:

$k_{\mathrm{eff}}=\frac{e_{\mathrm{m}}}{e_{\mathrm{m}}+e_{\mathrm{M}}} k_{\mathrm{s}}^{\mathrm{m}}+\frac{e_{\mathrm{M}}}{e_{\mathrm{m}}+e_{\mathrm{M}}} k_{\mathrm{s}}^{\mathrm{M}}$

where $e$ is the void ratio, $k_{\mathrm{s}}$ is the saturated hydraulic conductivity and the subscripts $m$ and $M$, respectively, indicate the micropore and the macropore.

We will now propose a methodology to estimate the three types of hydraulic conductivity considering the influence of salinity of the infiltrating water. We start first with the adoption of the semi-theoretical equation from Kozeny [22] and Carman [6] for a single-porosity medium: 
(a)

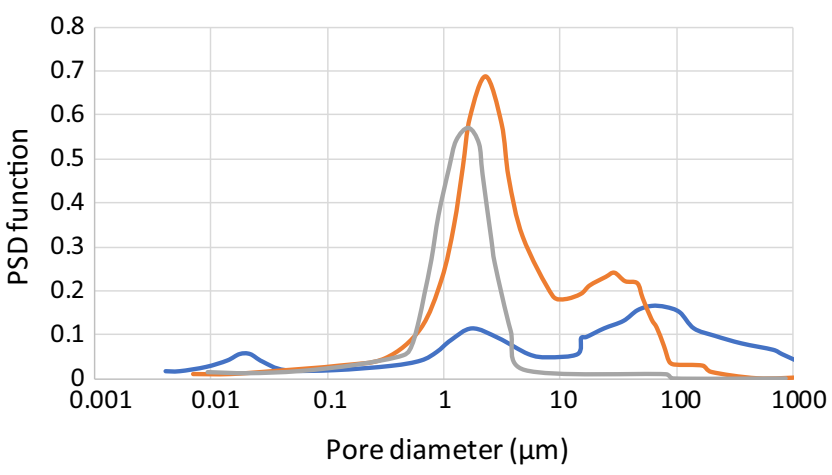

$-4 \mathrm{M} \mathrm{NaCl} \longrightarrow 1 \mathrm{M} \mathrm{NaCl} \longrightarrow$ Distilled water (b)

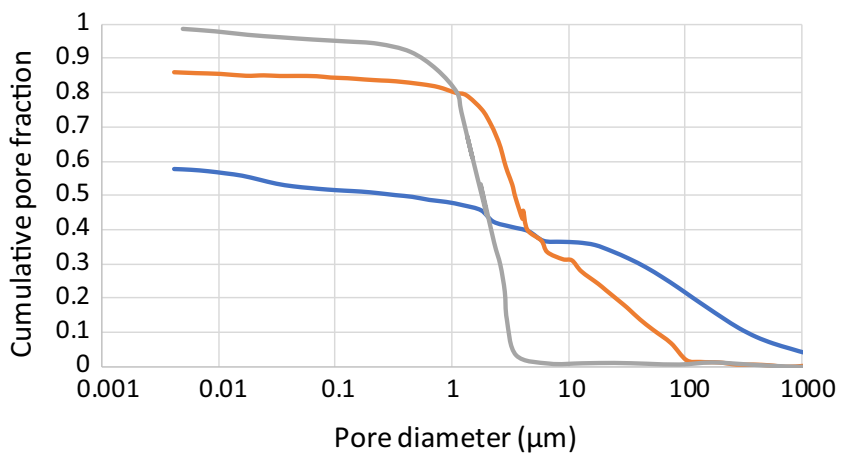

$\longrightarrow 4 \mathrm{M} \mathrm{NaCl} \longrightarrow 1 \mathrm{M} \mathrm{NaCl} \longrightarrow$ Distilled water

(c)

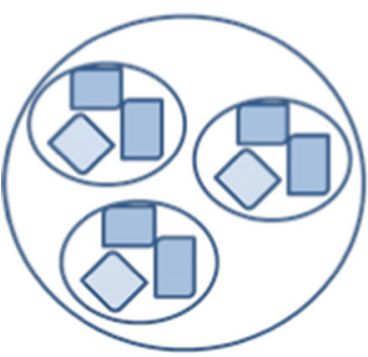

1. Initial state

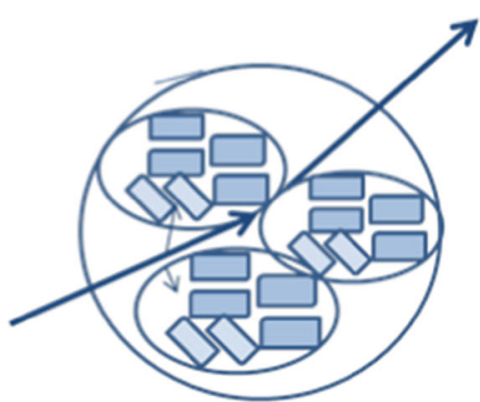

2. Water infiltrates micropores DDL expand

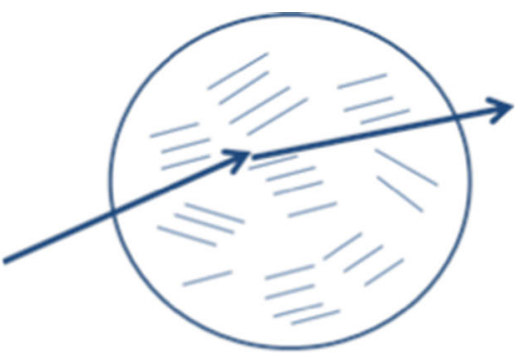

3a. DI water: DDL expand macropores disappear

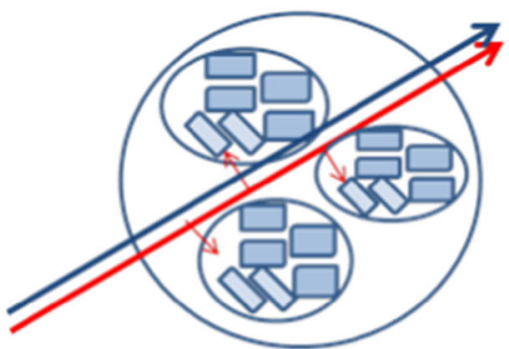

3b. Brine: Solutes diffuse into micropores-DDL shrinks

Fig. 2 a Pore size distribution, b cumulative pore fraction of sand/bentonite mixture saturated with various concentrations of pore fluids (after Manca et al. [29], initial void ratio e $=0.78$ ) and $\mathbf{c}$ schematic diagram for sequential development of structures and water (blue line) and solute (red line) migrations under brine infiltration (color figure online)

$k=\frac{\gamma}{\mu C_{\mathrm{kc}} S^{2}} \frac{e^{3}}{1+e}$

where $k$ is the saturated hydraulic conductivity $(\mathrm{m} / \mathrm{s})$ of the single-porosity medium, $\gamma$ is specific gravity, $\mu$ is pore fluid viscosity ( $\mathrm{Pa} \mathrm{s}), S$ is specific surface area in unit volume of solid phase, $C_{\mathrm{kc}}$ is the Kozeny-Carman empirical coefficient, $e$ is void ratio. Using experimental data from various sources for bentonite infiltrated with DI water (Fig. 3), the effective hydraulic conductivity $(\mathrm{m} / \mathrm{s})$ of the bulk medium can be represented by a power law function that is very similar to the Kozeny-Carman equation: $k=10^{-13} \frac{e^{3.74}}{1+e}$

We have $\frac{\gamma}{\mu}=7.6 \times 10^{6} 1 / \mathrm{m} \mathrm{s}$. The specific surface area $S$ in unit volume of typical MX-80 can be calculated from specific surface area (SSA) value of $561 \mathrm{~m}^{2} / \mathrm{g}$ [5], which leads to $S=\mathrm{SSA} * \gamma_{s} \times 10^{6}=1.51 \times 10^{9} 1 / \mathrm{m}$.

Therefore, the model constant $C_{\mathrm{kc}}$ can be estimated for bentonite as

$C_{\mathrm{kc}}=\frac{\gamma}{\mu S^{2}} 10^{13} e^{-0.74}=33.3 * e^{-0.74}$ 


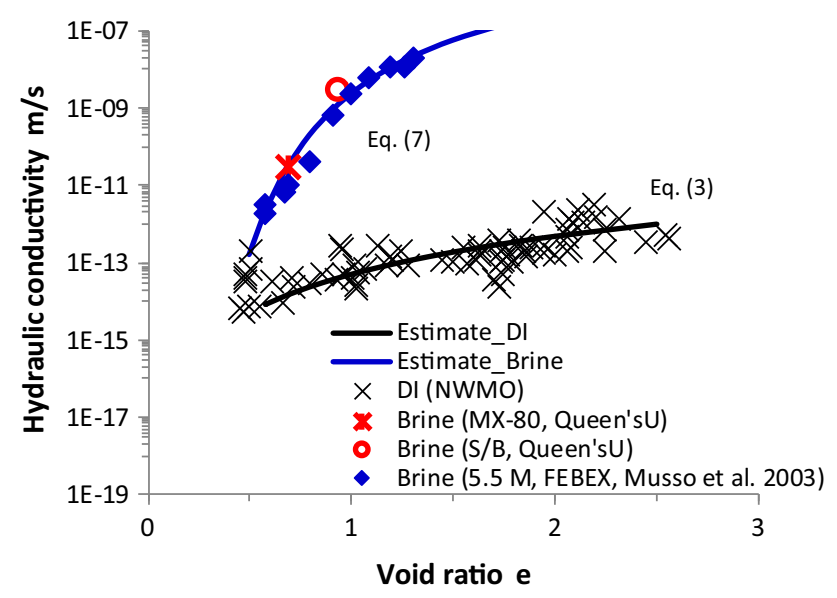

Fig. 3 Dependence of hydraulic conductivity of bentonite on void ratio and salinity (solid symbols with chemical concentrations represent the FEBEX bentonite from Musso et al. [32]; the MX-80 data from Queen's University [42]; the DI_NWMO data from Man, Martino [28])

This $C_{\mathrm{kc}}$ value could be much larger than the well-recognized value of 5 for packed sandy soils as indicated by Carrier III [7]. This is likely due to the thick electric double layer of clay particles, that greatly hinders the transmissivity of compacted clay, through electric-hydraulic-coupled effects [25] and thus increases the $C_{\mathrm{kc}}$ factor. It is shown by the above analysis that the Kozeny-Carman equation is suitable for permeability estimation regarding the specific case of MX-80 bentonite hydrated with DI water.

As previously discussed, when bentonite is saturated with DI water, the macropores practically disappear; therefore, $k_{\text {eff }}=k_{\mathrm{s}}^{\mathrm{m}}$, and the effective hydraulic conductivity of bentonite in this case, and as represented by Eq. 3, is assumed to be equal to the micropore permeability. Therefore, the saturated micropore hydraulic conductivity $k_{\mathrm{s}}^{\mathrm{m}}$ is assumed to be given by:

$k_{\mathrm{s}}^{\mathrm{m}}=10^{-13} \frac{e_{\mathrm{m}}^{3.74}}{\left(1+e_{\mathrm{m}}\right)}$

$e_{\mathrm{m}}$, the micropore void ratio could be determined by the micropore gravimetric water content $\left(w^{\mathrm{m}}\right)$ as

$e_{\mathrm{m}}=w^{\mathrm{m}} G_{\mathrm{s}}$

Note that $w^{\mathrm{m}}$ is distinct from the total water content $w$ and is governed by the osmotic suction of chemical solution.

The effective hydraulic conductivity of compacted MX80 bentonite with brine was determined by experiments. The data that come from different sources as shown in Fig. 3 can best fit with an empirical equation of

$k_{\text {eff }}=10^{-9} e^{11.86}$ where $e$ is the total void ratio given as $e=e_{\mathrm{m}}+e_{\mathrm{M}}$.

Being orders of magnitude higher than the micropore permeability, the macropore hydraulic conductivity with brine infiltration could be treated as equivalent to the overall effective permeability of the sample, i.e.

$k_{\mathrm{s}}^{\mathrm{M}} \approx k_{\mathrm{eff}}$

\subsection{Chemical transport properties: tortuosity and diffusion}

For the macropores, the free diffusion coefficient is assumed to prevail, i.e. $D_{\mathrm{e}}=D_{0}$. For the micropores, tortuosity significantly affects the diffusion of solutes. The relation between tortuosity and diffusion in the micropores can be illustrated by looking at the 1-D solute transport equation:

$\frac{\partial C}{\partial t}=\frac{D_{\mathrm{e}}}{n+\rho_{\mathrm{b}} K_{\mathrm{d}}} \frac{\partial^{2} C}{\partial x^{2}}=D_{\mathrm{a}} \frac{\partial^{2} C}{\partial x^{2}}$

where $n$ is porosity, $\rho_{\mathrm{b}}$ is bulk density, $K_{\mathrm{d}}$ is the partition coefficient that takes into account sorption of the solutes on the solid phase, $C$ is solute concentration, $D_{\mathrm{e}}$ is the effective diffusion coefficient, $D_{\mathrm{a}}$ is the apparent diffusion coefficient $\left(D_{\mathrm{a}}=\frac{D_{\mathrm{e}}}{n+\rho K_{\mathrm{d}}}\right), t$ is time and $x$ is the length.

For non-sorptive chemicals like $\mathrm{Cl}^{-}, \mathrm{ClO}^{4-}$ and $\mathrm{I}^{-}, K_{\mathrm{d}}$ is negligible. Then we can simplify the diffusion coefficient into

$D_{\mathrm{e}}=D_{\mathrm{a}} n$

Many test data $[4,35,51]$ show an exponential decay or power law relationship (Fig. 4) between the ratio of apparent diffusion coefficient to free diffusion coefficient $\left(D_{0}\right)$ and porosity for bentonite infiltrated with DI water or slightly salt solution in the following form:

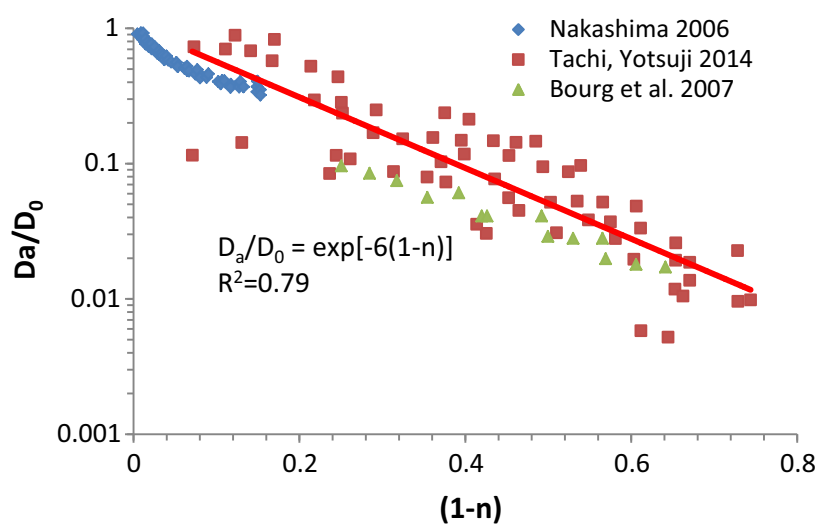

Fig. 4 Diffusion coefficients of non-sorptive species in compacted bentonite 
$\frac{D_{\mathrm{a}}}{D_{0}}=\exp [-6(1-n)]$

Therefore,

$D_{\mathrm{e}}=n D_{0} \exp [-6(1-n)]$

\subsection{WRC for MX-80 bentonite}

Soil suction is defined as the energy required for extracting a unit volume of water from a soil in order to overcome retention mechanisms that exist in that soil [14]. For the current problem under study, three distinct water retention mechanisms are considered: water adsorption, capillary retention and osmosis. The total suction $\left(S_{\mathrm{u}}\right)$ is equal to the sum of matric suction $\left(p_{\mathrm{m}}\right)$ and osmotic suction $(\pi)$, according to the definition of soil suction by the International Society of Soil Science and others [23, 52]. Water adsorption upon clay minerals at high suction levels and capillary retention at lower suction levels [10, 48] are responsible for matric suction. Water adsorption is mainly governed by the physicochemistry of clay minerals and takes place in the intra-aggregate micropores in terms of electric double layers between the clay stacks [48]. Experiments have shown that the total void ratio or dry density has no effect on the WRC of MX-80 bentonite at suction levels higher than $10 \mathrm{MPa}$, suggesting that the predominant mechanism of water retention is adsorption in that high suction range. The second mechanism of retention is mainly attributable to capillarity effects in the inter-aggregate macropores when the soil approaches a saturated state, e.g. suction becomes less than the air entry value (AEV). For the purpose of modelling water flow in MX-80 within a dual-porosity framework, we need relationships for the WRC in both types of pores that take into consideration the above three types of water retention mechanisms. These relationships are derived as follows.

\subsubsection{Macropore WRC}

The macropore WRC is derived from Dieudonne et al. [10], who proposed a model for the macropore water retention curve and calibrated it successfully against experimental results for MX-80 bentonite. Their approach is based on the following assumptions:

(1) Adsorption and capillarity are the respective mechanisms for water retention in the micropore and macropore; osmosis is not considered;

(2) the AEV $\alpha$ could be expressed as a function of macropore void ratio $e_{\mathrm{M}}, \alpha=0.2 / e_{\mathrm{M}}(\mathrm{MPa})$;

(3) the micropore void ratio $\left(e_{\mathrm{m}}\right)$ could be expressed as a function of water ratio (ratio of volume of water over solid volume) $e_{\mathrm{w}}, e_{\mathrm{m}}=0.48\left(e_{\mathrm{w}}\right)^{2}+0.1 e_{\mathrm{w}}+0.31 ;$

(4) the water ratio is dependent on the gravimetric water content, $e_{\mathrm{w}}=G_{\mathrm{s}} w$.

Based on the above assumptions, Dieudonné et al. [10] fitted the van Genuchten equation to experimental data. The data points from those authors for compacted MX-80 bentonite at a dry density of $1.6 \mathrm{~g} / \mathrm{cm}^{3}$ are plotted as square dots in Fig. 5. We applied the following Brooks-Corey equation in order to best fit the data points as shown in Fig. 5:

$S_{\mathrm{e}}=\left(0.4 S_{\mathrm{u}}\right)^{-\frac{1}{1.6}}$

where $S_{\mathrm{e}}$ is the saturation degree.

\subsubsection{Micropore WRC}

The total suction of MX- 80 bentonite hydrated with both DI water and brine solution has been measured by the chilled mirror technique [42] and are plotted against gravimetric water content as shown in Fig. 6 . The chilled mirror technique measures the vapour pressure and gives the total suction of the bentonite specimen. For the case of DI water, no osmotic suction exists; therefore, the total suction is equal to the matric suction. For the case of brine, assuming thermodynamic equilibrium, the measured total suction $S_{\mathrm{u}}$ should be the same for both pore structures. Furthermore, due to the relatively short duration of the WRC test, the amount of solutes migrating into the micropore could be neglected. Therefore, osmotic suction in the micropore could be neglected, and matric suction in the micropore would be approximately equal to the total suction (i.e. $p_{\mathrm{m}}=S_{\mathrm{u}}$ ). We propose the following empirical relationship for the WRC of MX-80 bentonite hydrated with DI water:

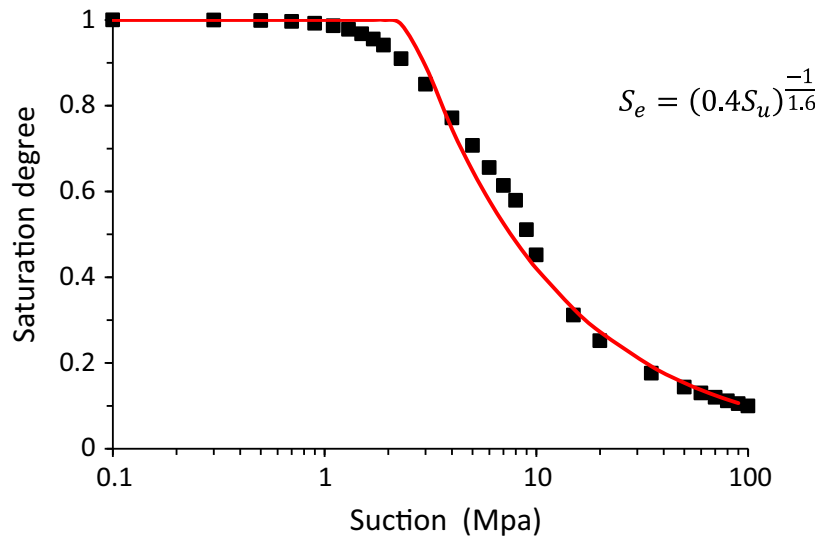

Fig. 5 The predicted WRC (line) for the macropore by the BrooksCorey model $S_{\mathrm{e}}=\left(\alpha S_{\mathrm{u}}\right)^{-n}$ with $\alpha=0.4 \mathrm{MPa}^{-1}, n=0.625$ and $\rho_{\mathrm{d}}=1.6$ fitted to experimental data on MX-80 (square dots) from Dieudonne et al. [10]) 


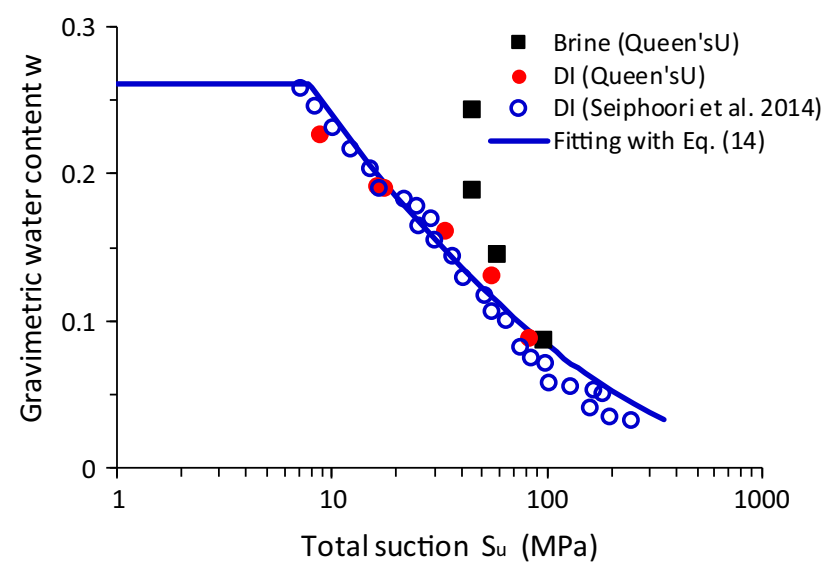

Fig. 6 WRC of MX-80 bentonite with respect to total suction

$\sqrt{w}=-0.2 * \log \left(\frac{p_{\mathrm{m}}}{S_{\mathrm{ut}}}\right), \quad S_{\mathrm{ut}}=2800$ for DI water

where $p_{\mathrm{m}}$ is matric suction, $w$ is water content and $S_{\mathrm{ut}}$ is the suction at which $w=0$. As previously discussed, when MX-80 is infiltrated with DI water, the clay aggregates break down and eventually all macropores disappear. Therefore, Eq. (14) is regarded as representative of micropore WRC for DI water.

$S_{e}=\left(0.4 S_{u}\right)^{\frac{-1}{1.6}}$

The WRC for the case of brine as shown in Fig. 6 is not in its equilibrium state when bentonite is in contact with brine solution, since those measurements were performed in a relatively short period of time. With the migration of chemicals into the micropore space, the WRC will evolve due to the gradual increase in osmotic suction in the micropores. In this study, we address this chemical-dependent variation of micropore WRC by generalizing Eq. (14). This generalization is done by making the suction toe $\left(S_{\mathrm{ut}}\right)$ dependent on the solute concentration inside the micropore. An exponential function is proposed for this relationship as below, and its parameters were obtained by calibration against swelling test data from Queen's University by an iterative regression method:

$S_{\text {ut }}=S_{\text {ur }}+\vartheta e^{-A * C^{\mathrm{m}}}$

where the calibrated model parameters $S_{\mathrm{ur}}=100 \mathrm{MPa}$; $\vartheta=2700 \mathrm{MPa} ; \mathrm{A}=0.0006 ; C^{\mathrm{m}}$ is the micropore solute concentration in the unit of $\mathrm{mol} / \mathrm{m}^{3}$.

\subsection{Swelling pressure at various dry densities and salinities}

Figure 7 shows the variation of swelling pressure of MX80 bentonite with effective montmorillonite dry density (EMDD) at various salinity conditions. EMDD is defined as the mass of swelling clay minerals present in a sample divided by the volumes of voids and swelling clay minerals. Brine generally leads to a decrease in swelling pressure for bentonite. The logarithm of swelling pressure is found to change linearly with EMDD. The test data for model water obtained from Queen's University follow the general trend as reported in existing studies [11]. As discussed later, in the case of brine infiltration, the data from Queen's University show that the swelling pressure increases rapidly to peak values. Those peak values are shown in Fig. 7a. At very long periods of time (of the order of 1 year or more), the swelling pressure decreases to smaller steadystate values, as shown in Fig. 7b. That long-term reduction in swelling pressure is likely attributed to the chemistry of the model water, i.e. the high concentration of $\mathrm{Ca}, \mathrm{Mg}, \mathrm{K}$. Herbert et al. [18] observed a similar trend in swelling pressure decrease under chemical influence.

\subsection{HMC-coupled model for MX-80 bentonite}

\subsubsection{Key assumptions}

\section{(a) Dual-porosity structure}

As discussed previously, two types of pore structures, the intra-aggregate micropores and the inter-aggregate macropores, are considered in this study. The relevant proportion of each porosity varies with both matric suction and osmotic suction. The microstructural volume change could cause changes in various parameters such as hydraulic conductivity, water retention capacity, diffusion coefficient and swelling pressure measurement. Therefore, a conceptual model was established in the dual-porosity framework as shown in Fig. 8. According to this conceptual model, fluid flow and chemical transport processes occur simultaneously in both pore structures, with exchange of fluid and chemicals between the two structures.

\section{(b) Chemical-dependent WRC}

Hydration with brine solution through the macropore may cause perturbation to the salinity in the micropore. The salts entering the micropore modify the electrochemical equilibrium in the electric double layer in the micropore space, resulting in a change in the WRC. Therefore, an appropriate treatment of the chemistry-dependent WRC is critical to reflect the time-dependent dynamic process of clay-chemical interactions.

\section{(c) Water content-dependent microporosity}

In highly expansive bentonite, water is preferentially sorbed to the mineral surface and interlayers due to electrochemical interactions. Navarro et al. [38] believed that at 


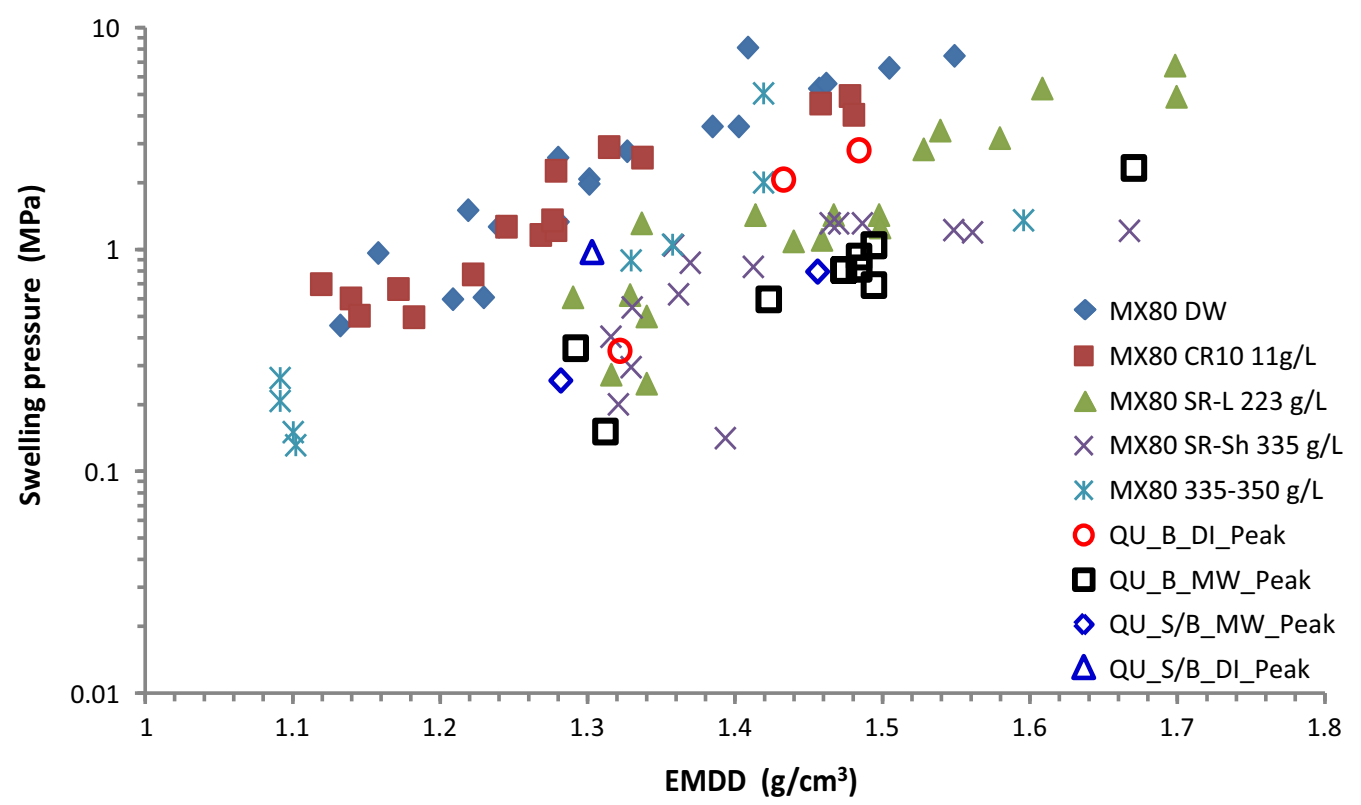

(a) Peak values of swelling pressure from Queen's University

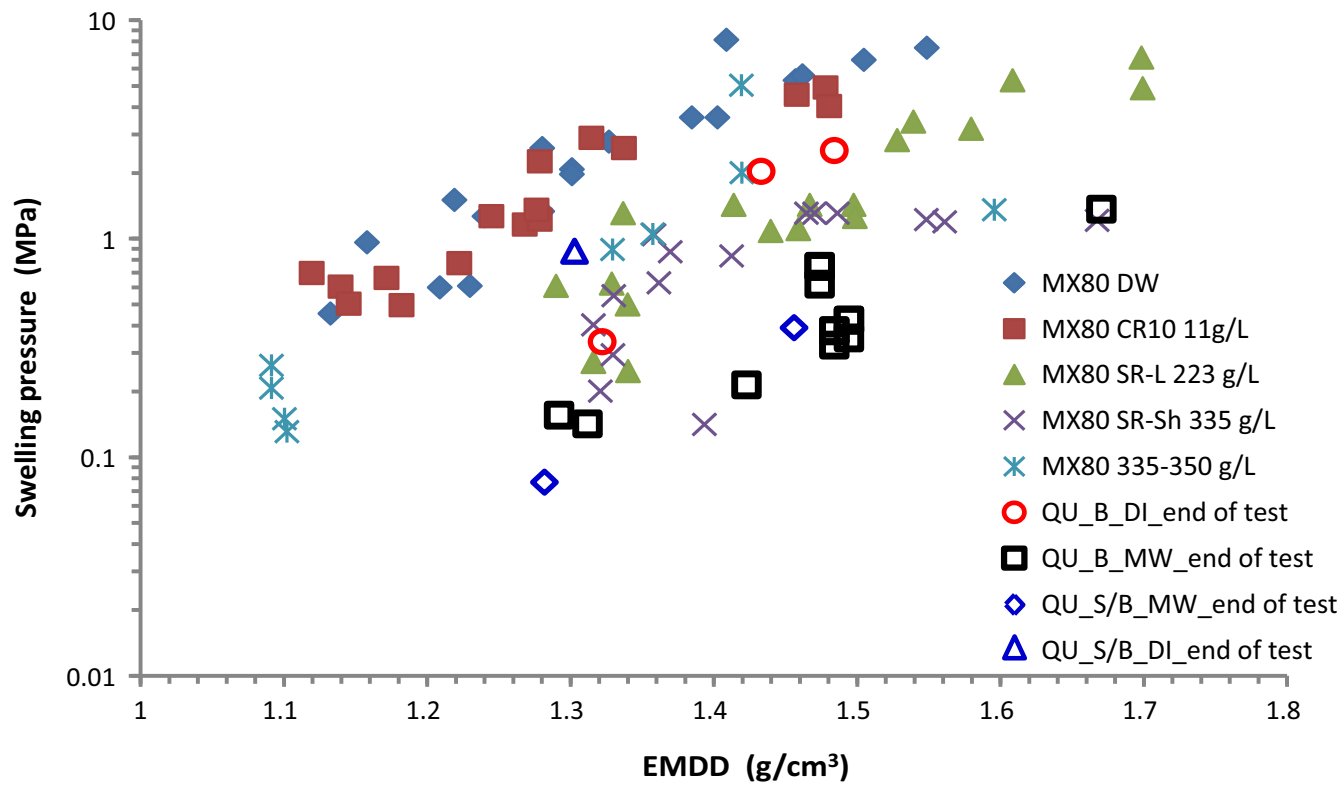

(b) Steady- State values of swelling pressure from Queen's University

Fig. 7 Variation of swelling pressure of MX-80 bentonite with effective montmorillonite dry density (EMDD) for various salinity conditionsModified from [11]; QU stands for Queen's University, with peak values reported in a and steady-state values reported in b

high suction levels, most of the water is sorbed water in the micropores, and the water in the macropores can be drained completely even though the micropores remain saturated. In this study, the microporosity is assumed to be solely dependent on the gravimetric water content when matric suction $S_{\mathrm{u}}>\mathrm{AEV}$. The swelling of bentonite is primarily attributed to the penetration of water into the diffuse layer and interlayer space of clay minerals (or intra-aggregate space). Therefore, the microporosity varies with the change in water content in the micropore. This assumption is consistent with Navarro et al. [39].

(d) Membrane effect

Semi-permeable membrane effect is prominent for bentonite in contact with saline water [21, 25, 27]. The membrane has a filtering effect: it delays movement of 

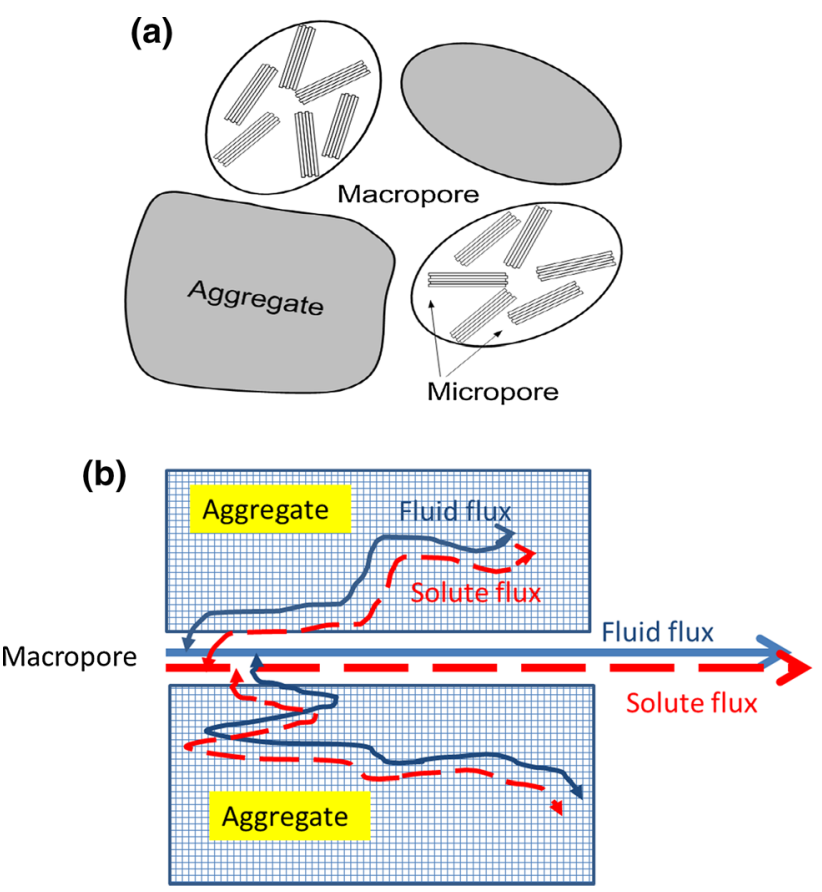

Fig. 8 Schematic illustration of a the dual-porosity structure in pore space and $\mathbf{b}$ the conceptual model for fluid and solute fluxes and exchange between pore structures

solutes with respect to the flow of water into the micropores.

\subsection{Hydraulic flow equations}

Let us consider a representative element of porous media with a single-porosity structure, and let $\mathrm{n}$ be porosity, $S_{\mathrm{e}}$ the degree of saturation, $\rho_{l}$ the fluid density, $G_{\mathrm{s}}$ the specific gravity of solid and $w$ the gravimetric water content. By assuming that $G_{\mathrm{s}}$ stays constant over time (i.e. no dissolution or precipitation reactions taking place), we can write the following equation of fluid mass conservation:

$\frac{\partial}{\partial t}\left(\rho_{l} n S_{\mathrm{e}}\right)-\nabla \frac{k_{\mathrm{s}} k_{\mathrm{r}}}{\mu} \rho_{l} \nabla P=Q$

where $P$ is the net pore pressure, $k_{\mathrm{s}}$ is saturated intrinsic permeability, $k_{\mathrm{r}}$ is the relative permeability and $Q$ is the source term. The net pore pressure $P$ is composed of water pressure $(p)$ and osmotic suction $(\pi)$ in the form of

$P=p-\pi$

where $p=u_{\mathrm{a}}-p_{\mathrm{m}}$ if $S_{\mathrm{e}}<1$.

In the saturated state, $p$ represents the pore pressure measurable by pore pressure transducer. The relationship between different suction and pore pressure parameters is as follows. Let $S_{\mathrm{u}}$ be the total suction, then $S_{\mathrm{u}}=p_{\mathrm{m}}+\pi$. The matric suction $p_{\mathrm{m}}=u_{\mathrm{a}}-p$, with $u_{\mathrm{a}}$ the air pressure, considered as atmospheric (0), and $\mathrm{p}$ the water pressure, then $p=-p_{\mathrm{m}}$. Then, the net pore pressure $P$ is the negative of total suction as $P=-S_{\mathrm{u}}=p-\pi$

From fundamental phase relationship, we get

$n S_{\mathrm{e}}=(1-n) G_{\mathrm{s}} w$

Differentiation of the first term of Eq. (16) leads to

$$
\begin{aligned}
\frac{\partial}{\partial t}\left(\rho_{l} n S_{\mathrm{e}}\right)= & \frac{\partial}{\partial t}\left[\rho_{l}(1-n) G_{\mathrm{s}} w\right]=(1-n) G_{\mathrm{s}} \frac{\partial}{\partial t}\left(\rho_{l} w\right) \\
& +\rho_{l} G_{\mathrm{s}} w \frac{\partial}{\partial t}(1-n) \\
= & (\alpha)+(\beta)
\end{aligned}
$$

Since pore fluid is compressible and water content is suction dependent, we can further differentiate the above equation with respect to net pore pressure $P$ as

$(\alpha)=(1-n) G_{\mathrm{s}} \frac{\partial}{\partial P}\left(\rho_{l} w\right) \frac{\partial P}{\partial t}$

The osmotic suction is dependent on solute concentration $C$ in the form of

$\pi=k_{\mathrm{c}} C$

where $k_{\mathrm{c}}=\mathrm{RT}$ for dilute salt solutions $(C<0.1 \mathrm{M}), R$ is ideal gas constant $(8.314 \mathrm{kPa} \mathrm{L} /(\mathrm{K} \mathrm{mol})), T$ is temperature $(K)$, in which case $k_{\mathrm{c}}=8.314 \mathrm{kPa} \cdot \mathrm{L} /(\mathrm{K} \mathrm{mol}) * 300 \mathrm{~K} \approx$ $2.5 \mathrm{MPa} \mathrm{L} / \mathrm{mol}$. For concentrated brine, this formula has to be corrected, i.e. $1 \mathrm{M} \mathrm{NaCl}$ solution has an osmotic suction of $4.8 \mathrm{MPa}$. For multivalent chemical mixtures such as the model saline water used in this study $(C=4.6 \mathrm{~mol} / \mathrm{L}$ in terms of total molarity of chemicals including $2.6 \mathrm{M} \mathrm{NaCl}, 0.54 \mathrm{M} \mathrm{CaCl}_{2}, 1 \mathrm{M} \mathrm{KCl}, 0.43 \mathrm{M}$ $\mathrm{MgCl}_{2}$ and $0.01 \mathrm{M} \mathrm{MgSO}_{4}$ ), its osmotic suction cannot be predicted by the above correlations. Instead, it was measured to be $40.6 \mathrm{MPa}$ with the chilled mirror device, suggesting a constant $k_{\mathrm{c}}=8.83 \mathrm{MPa} \mathrm{L} / \mathrm{mol}$. Note that the parameter $k_{\mathrm{c}}$ is assumed as constant in the following derivations for simplicity, though it is somewhat nonlinear within a large range of concentrations.

Then equation part $(\alpha)$ becomes

$$
\begin{aligned}
(\alpha) & =(1-n) G_{s}\left[\frac{\partial}{\partial p}\left(\rho_{l} w\right) \frac{\partial p}{\partial t}+\frac{\partial}{\partial \pi}\left(\rho_{l} w\right) \frac{\partial \pi}{\partial t}\right] \\
& =(1-n) G_{s}\left[\left(\chi_{f} \rho_{l} w+\frac{B}{p} \rho_{l}\right) \frac{\partial p}{\partial t}+\frac{\partial}{\partial C}\left(\rho_{l} w\right) \frac{\partial C}{\partial t}\right]
\end{aligned}
$$

where $B$ is the slope of $\mathrm{w}-\log \left(S_{\mathrm{u}}\right)$ relationship for bentonite and $\chi_{\mathrm{f}}$ is the compressibility of pore fluid.

Note that fluid density varies with chemical concentration, which leads to

$$
\frac{\partial}{\partial C}\left(\rho_{l} w\right)=w \frac{\partial \rho_{l}}{\partial C}+\rho_{l} \frac{\partial w}{\partial C}=k_{2} w+k_{1} \rho_{l}
$$


where $k_{1}$ and $k_{2}$ are material properties that are given as $k_{2}=\frac{\partial \rho_{l}}{\partial C}$, and $k_{1}=\frac{\partial w}{\partial C}=0$ as water content is independent of salinity.

Therefore,

$(\alpha)=(1-n) G_{\mathrm{s}}\left[\left(\chi_{f} \rho_{l} w+\frac{B}{p} \rho_{l}\right) \frac{\partial p}{\partial t}+k_{2} w \frac{\partial C}{\partial t}\right]$.

Meanwhile,

$$
\begin{aligned}
(\beta) & =\rho_{l} G_{\mathrm{s}} w \frac{\partial}{\partial t}(1-n)=-\rho_{l} G_{\mathrm{s}} w \frac{\partial n}{\partial t} \\
& =-\rho_{l} G_{\mathrm{s}} w\left(\frac{\partial n}{\partial \sigma^{\prime}} \frac{\partial \sigma^{\prime}}{\partial t}+\frac{\partial n}{\partial P} \frac{\partial P}{\partial t}\right) .
\end{aligned}
$$

Then,

$$
\begin{aligned}
(\beta) & =-\rho_{l} G_{\mathrm{s}} w\left[-\frac{\partial \varepsilon_{\mathrm{v}}}{\partial t}+\chi_{\mathrm{s}} n\left(\frac{\partial p}{\partial t}-\frac{\partial \pi}{\partial t}\right)\right] \\
& =-\rho_{l} G_{\mathrm{s}} w\left[-\frac{\partial \varepsilon_{\mathrm{v}}}{\partial t}-\chi_{\mathrm{s}} n k_{\mathrm{c}} \frac{\partial C}{\partial t}+\chi_{\mathrm{s}} n \frac{\partial p}{\partial t}\right]
\end{aligned}
$$

where $\chi_{\mathrm{s}}$ is the compressibility of the solid matrix, $\varepsilon_{\mathrm{v}}$ is the volumetric strain and $\sigma^{\prime}$ is the effective stress.

Finally, we get a general expression for the flow equation in a deformable unsaturated porous medium, taking into consideration variable water density

$$
\begin{gathered}
G_{\mathrm{s}} \rho_{l} w\left[(1-n)\left(\chi_{\mathrm{f}}+\frac{B}{p w}\right)-n \chi_{\mathrm{s}}\right] \frac{\partial p}{\partial t}-\nabla \frac{k_{\mathrm{s}} k_{\mathrm{r}}}{\mu} \rho_{l} \nabla p \\
+G_{\mathrm{s}} \rho_{l} w\left[n \chi_{\mathrm{s}} k_{\mathrm{c}}+(1-n) \frac{k_{2}}{\rho_{l}}\right] \frac{\partial C}{\partial t} \\
+\nabla \frac{k_{\mathrm{s}} k_{\mathrm{r}}}{\mu} \rho_{l} k_{\mathrm{c}} \nabla C=-G_{\mathrm{s}} \rho_{l} w \frac{\partial \varepsilon_{\mathrm{v}}}{\partial t}+Q .
\end{gathered}
$$

\subsubsection{Dual-porosity flow equations}

Based on Eq. (27) for a single-porosity medium, we can derive the flow equations for a dual-porosity medium as follows, where the superscripts $m$ and $M$ for a parameter, respectively, qualify that parameter as associated with the micropore or the macropore.

In micropore,

$$
\begin{aligned}
& G_{\mathrm{s}} \rho_{l} w^{\mathrm{m}}\left[\left(1-n^{\mathrm{m}}\right)\left(\chi_{\mathrm{f}}+\frac{B}{p^{\mathrm{m}} w^{\mathrm{m}}}\right)-n^{\mathrm{m}} \chi_{\mathrm{s}}\right] \frac{\partial p^{\mathrm{m}}}{\partial t} \\
& -\nabla \frac{k_{\mathrm{s}}^{\mathrm{m}} k_{\mathrm{r}}}{\mu} \rho_{l} \nabla p^{\mathrm{m}}+G_{\mathrm{s}} \rho_{l} w^{\mathrm{m}}\left[n^{\mathrm{m}} \chi_{\mathrm{s}} k_{\mathrm{c}}+\left(1-n^{\mathrm{m}}\right) \frac{k_{2}}{\rho_{l}}\right] \frac{\partial C^{\mathrm{m}}}{\partial t} \\
& +\nabla \frac{k_{\mathrm{s}}^{\mathrm{m}} k_{\mathrm{r}}}{\mu} \rho_{l} k_{\mathrm{c}} \nabla C^{\mathrm{m}}=-G_{\mathrm{s}} \rho_{l} w^{\mathrm{m}} \frac{\partial \varepsilon_{\mathrm{v}}^{\mathrm{m}}}{\partial t}+Q^{\mathrm{m}} .
\end{aligned}
$$

Taking into account the constitutive relationship for the microporosity, it is inferred that the micropores are mostly saturated or are close to full saturation
$\left(S_{\mathrm{e}}^{\mathrm{m}}=w^{\mathrm{m}} G_{\mathrm{s}} / e^{\mathrm{m}}=w^{\mathrm{m}} G_{\mathrm{s}} / w^{\mathrm{m}} G_{\mathrm{s}}=1\right)$. Then, the flow equation for the micropores can be reduced to the Darcy's flow form

$\frac{\partial}{\partial t}\left(\rho_{l} n^{\mathrm{m}}\right)-\nabla \frac{k_{\mathrm{s}}^{\mathrm{m}}}{\mu} \rho_{l}\left(\nabla p^{\mathrm{m}}-k_{\mathrm{c}} \nabla C^{\mathrm{m}}\right)=Q^{\mathrm{m}}$.

In macropore,

$$
\begin{aligned}
& G_{\mathrm{s}} \rho_{l} w^{\mathrm{M}}\left[\left(1-n^{\mathrm{M}}\right)\left(\chi_{\mathrm{f}}+\frac{B}{p^{\mathrm{M}} w^{\mathrm{M}}}\right)-n^{\mathrm{M}} \chi_{\mathrm{s}}\right] \frac{\partial p^{\mathrm{M}}}{\partial t} \\
& -\nabla \frac{k_{\mathrm{s}}^{\mathrm{M}} k_{\mathrm{r}}}{\mu} \rho_{l} \nabla p^{\mathrm{M}}+G_{\mathrm{s}} \rho_{l} w^{\mathrm{M}}\left[n^{\mathrm{M}} \chi_{\mathrm{s}} k_{\mathrm{c}}+\left(1-n^{\mathrm{M}}\right) \frac{k_{2}}{\rho_{l}}\right] \frac{\partial C^{\mathrm{M}}}{\partial t} \\
& +\nabla \frac{k_{\mathrm{s}}^{\mathrm{M}} k_{\mathrm{r}}}{\mu} \rho_{l} k_{\mathrm{c}} \nabla C^{\mathrm{M}}=-G_{\mathrm{s}} \rho_{l} w^{\mathrm{M}} \frac{\partial \varepsilon_{\mathrm{v}}^{\mathrm{M}}}{\partial t}+Q^{\mathrm{M}} .
\end{aligned}
$$

The volumetric strain can be linked to the porosity variation in the following form:

$\frac{\partial \varepsilon_{\mathrm{v}}^{\mathrm{m}}}{\partial t}=-\frac{\partial n^{\mathrm{m}}}{\partial t}$

$\frac{\partial \varepsilon_{\mathrm{v}}^{\mathrm{M}}}{\partial t}=-\frac{\partial n^{\mathrm{M}}}{\partial t}$

The water exchange rates between micropores and macropores take the following form:

$Q^{\mathrm{M}}=-a^{\mathrm{M}}$

$Q^{\mathrm{m}}=a^{\mathrm{M}}$

where

$a^{\mathrm{M}}=\bar{\alpha}\left(p^{\mathrm{m}}-p^{\mathrm{M}}-\pi^{\mathrm{m}}+\pi^{\mathrm{M}}\right)$

where $\bar{\alpha}$ is the fluid exchange rate that is assumed to be a function of the hydraulic conductivity of the micropore, i.e. $\bar{\alpha}=N k \rho_{l}$, where $N$ is a factor.

\subsection{Solute transport equations}

For solute transport in unsaturated porous media,

$\frac{\partial(\theta C)}{\partial t}=\nabla\left(D_{\mathrm{e}} \nabla C\right)-\nabla(v C)+Q_{\mathrm{c}}$

where $\theta$ is the volumetric water content, $D_{\mathrm{e}}$ is effective diffusion coefficient, $v$ is the Darcy's velocity of the pore fluid and $Q_{\mathrm{c}}$ is the source flux of chemicals.

Since,

$\theta=n S_{\mathrm{e}}$.

Then, we have

$\frac{\partial \theta C}{\partial t}=C n \frac{\partial S_{\mathrm{e}}}{\partial t}+C S_{\mathrm{e}} \frac{\partial n}{\partial t}+S_{\mathrm{e}} n \frac{\partial C}{\partial t}$.

By neglecting the compressibility of solid matrix and pore fluid, the variation of porosity is assumed to be 
dependent only on volumetric deformation due to variation of pore volume.

Therefore, we have

$S_{\mathrm{e}} n \frac{\partial C}{\partial t}=\nabla\left(D_{\mathrm{e}} \nabla C\right)-\nabla(v C)+Q_{\mathrm{c}}-C\left(n \frac{\partial S_{\mathrm{e}}}{\partial t}+S_{\mathrm{e}} \frac{\partial \varepsilon_{\mathrm{v}}}{\partial t}\right)$.

By taking into account the chemo-osmosis effect, or the so-called semi-permeable membrane effect of expansive soils [25], the solute transport equation can be given as

$$
\begin{aligned}
S_{\mathrm{e}} n \frac{\partial C}{\partial t}= & \nabla\left(D_{\mathrm{e}} \nabla C\right)-(1-\omega) \nabla(v C)+Q_{\mathrm{c}} \\
& -C\left(n \frac{\partial S_{\mathrm{e}}}{\partial t}+S_{\mathrm{e}} \frac{\partial \varepsilon_{\mathrm{v}}}{\partial t}\right)
\end{aligned}
$$

where $\omega$ is membrane coefficient, $\rho_{\mathrm{b}}$ is the bulk density.

In the macropore, a simplified version is obtained as follows by neglecting the semi-permeable membrane effect,

$$
\begin{aligned}
n^{\mathrm{M}} S_{\mathrm{e}}^{\mathrm{M}} \frac{\partial C^{\mathrm{M}}}{\partial t}= & D_{\mathrm{e}} \nabla^{2} C^{\mathrm{M}}-\nabla\left(v^{\mathrm{M}} C^{\mathrm{M}}\right)+Q_{\mathrm{c}}^{\mathrm{M}}-C^{\mathrm{M}} n^{\mathrm{M}} \frac{\partial S_{\mathrm{e}}^{\mathrm{M}}}{\partial t} \\
& -C^{\mathrm{M}} \frac{\partial \varepsilon_{\mathrm{v}}^{\mathrm{v}}}{\partial t} .
\end{aligned}
$$

In the micropore, the full equation has to be implemented

$$
\begin{aligned}
n^{\mathrm{m}} S_{\mathrm{e}}^{\mathrm{m}} \frac{\partial C^{\mathrm{m}}}{\partial t}= & \nabla\left(D_{\mathrm{e}} \nabla C^{\mathrm{m}}\right)-(1-\omega) \nabla\left(v^{\mathrm{m}} C^{\mathrm{m}}\right)+Q_{\mathrm{c}}^{\mathrm{m}} \\
& -C^{\mathrm{m}}\left(n^{\mathrm{m}} \frac{\partial S_{\mathrm{e}}^{\mathrm{m}}}{\partial t}+S_{\mathrm{e}}^{\mathrm{m}} \frac{\partial \varepsilon_{\mathrm{v}}}{\partial t}\right) .
\end{aligned}
$$

It is hypothesized here that the micropore is always nearly saturated. Therefore, the solute transport equation for the micropore can be reduced to

$$
\begin{aligned}
n^{\mathrm{m}} \frac{\partial C^{\mathrm{m}}}{\partial t}= & \nabla\left(D_{\mathrm{e}} \nabla C^{\mathrm{m}}\right)-(1-\omega) \nabla\left(v^{\mathrm{m}} C^{\mathrm{m}}\right)+Q_{\mathrm{c}}^{\mathrm{m}} \\
& -C^{\mathrm{m}} \frac{\partial \varepsilon_{\mathrm{v}}^{\mathrm{m}}}{\partial t} .
\end{aligned}
$$

Note that the membrane coefficient $\omega$ is calibrated here with data from Rowe and Brachman [42] and is found to be in the range 0.97-0.98. This gives an effective diffusion coefficient ratio (also given by Musso et al. [34]) in the range of $0.02-0.03$,

$D_{\mathrm{e}} / D_{0}=(1-\omega)$

According to Eq. (11), the apparent diffusion coefficient $D_{\mathrm{a}} / D_{0}=0.05-0.075$ when $n=0.41$ falls exactly on the regressed line in Fig. 4. Therefore, the calibrated membrane coefficient reasonably reflects the constricting effect of the diffuse layer at the clay-water interface. It also suggests the viability of the above form of expression Eq. (44).

The mass exchange flux $Q_{\mathrm{c}}$ is given as a function of fluid exchange rate $a^{\mathrm{M}}$ (flow out of micropore as $a^{\mathrm{M}}>0$ ) and mass transfer coefficient $\bar{D}$,

$Q_{\mathrm{c}}^{\mathrm{M}}=(1-\omega)\left[-a^{\mathrm{M}} C^{\overline{\mathrm{M}}}+\bar{D}\left(C^{\mathrm{m}}-C^{\mathrm{M}}\right)\right]$

And

$Q_{\mathrm{c}}^{\mathrm{m}}+Q_{\mathrm{c}}^{\mathrm{M}}=0$.

The convective mass flux is directional with respect to which concentration (i.e. $C^{\mathrm{m}}$ or $C^{\mathrm{M}}$ ) is carried by the fluid flow. We define

$C^{\mathrm{M}}=\left\{\begin{array}{lll}C^{\mathrm{m}}, & \text { if } & a^{\mathrm{M}} \geq 0 \\ C^{\mathrm{M}}, & \text { if } & a^{\mathrm{M}}<0\end{array}\right.$

The fluid exchange rate $a^{\mathrm{M}}$ is governed by pore pressure and osmotic suction differences. The mass transfer coefficient can be approximated to be

$\bar{D}=\frac{D_{e}}{L_{c}}$

where $L_{\mathrm{c}}$ is the characteristic length of the clay aggregate. Musso et al. [34] proposed a similar concept of mass exchange between dual porosities and developed a mathematical equation in exponential form for the transfer coefficient

$\bar{D}=\alpha \exp \left(-\mathrm{HC}^{\mathrm{M}}\right)$

where $\alpha$ and $H$ are two parameters to be calibrated by experiments, which were reported to be 0.8 and 8 , respectively, for MX-80 bentonite in contact with $\mathrm{NaCl}$ solution [34].

It is assumed in this study that the salinity in the micropore dominates the mass exchange rate. Inside the clay aggregate, the void ratio is greatly dependent on the DDL behaviour. We modify Eq. (49) to correlate the transfer coefficient with the chemical concentration in micropore

$\bar{D}=\frac{D_{\mathrm{e}}}{L_{\mathrm{c}}} \exp \left(-\mathrm{HC}^{\mathrm{m}}\right)$.

Our numerical simulation of brine-bentonite interaction leads to the following set of parameters, i.e. $L_{\mathrm{c}}=10 \mu \mathrm{m}$, $H=0.004$ (B_1.6 sample) for salinity $C^{\mathrm{m}}$ in the unit of molar $/ \mathrm{m}^{3}$.

\subsection{Constitutive relationship for mechanical behaviour}

The general constitutive relationship for the mechanical behaviour of unsaturated expansive soil can be given as 
$\boldsymbol{\sigma}=\mathbf{D} \cdot\left(\varepsilon-\varepsilon_{p}-\varepsilon_{s}\right)$

where $\boldsymbol{\sigma}$ is the total stress, $\mathbf{D}$ is the elastic stiffness matrix, $\varepsilon_{p}$ is the plastic strain and $\varepsilon_{s}$ is the swelling strain that occurs mainly from the expansion/shrinkage of the DDL in the micropore. In the case of constant volume swelling, the plastic strain is assumed to be negligible.

Assuming that the degree of saturation in the micropore is close to 1 , the void ratio $e_{\mathrm{m}}$ is related to the water content $w^{\mathrm{m}}$ through the phase relationship $e_{\mathrm{m}}=G_{\mathrm{s}} w^{\mathrm{m}}=\left(\rho_{\mathrm{s}} / \rho_{\mathrm{w}}\right)$ $w^{\mathrm{m}}$, where $\rho_{\mathrm{w}}$ is the density of pure water. The microporosity is then linearly correlated with the gravimetric water content $(w)$ in the form of

$w^{\mathrm{m}}=\frac{e_{\mathrm{m}} X \rho_{l}}{\rho_{\mathrm{s}}}$

where $X$ is mass ratio of water over total mass of saline water and $\rho_{l}$ is the density of saline water, which is larger than that of pure water. Therefore, the swelling strain associated with the micropore deformation is given as

$\mathrm{d} \varepsilon_{\mathrm{s}}=\frac{\rho_{\mathrm{s}}}{X \rho_{l}} \frac{\mathrm{d} w^{\mathrm{m}}}{1+e_{0}}$

where $w^{\mathrm{m}}$ is gravimetric water content in the micropore. In accord with model assumption $(c)$, and supported by the analysis of WRC in the double structures, the micropore water content can be approximated as equal to the total gravimetric water content, i.e. $w^{\mathrm{m}} \cong w_{\text {total }}$.

The mass ratio $X$ is not a constant. A linear function of $X$ for saline water of various concentrations leads to the following correlation

$X=1-5.87 \times 10^{-5} * C$.

In this study, the mass of $1 \mathrm{~L}$ model water was measured as $1223.1 \mathrm{~g}$. The total dissolved salt (TDS) of the Queen's University's model water (MW) supernatant was $328.9 \mathrm{~g} /$ L. In this case, the mass of DI water $(894.2 \mathrm{~g})$ was calculated as $73 \%$ of the mass of $1 \mathrm{~L}$ of MW2 supernatant. Therefore, $X=0.73$ is justifiable for saline water of $\rho_{l}=1223 \mathrm{~kg} / \mathrm{m}^{3}$. Then, $e_{\mathrm{m}}=\frac{w \rho_{\mathrm{s}}}{X \rho_{l}}=\frac{2.75}{0.73 * 1.223} w=3.08 \mathrm{w}$.

Using the above relationship, we can predict the ratio of micropore to total pore void ratios, defined as

$f_{\mathrm{m}}=\frac{e_{\mathrm{m}}}{e_{0}}$.

This parameter can be a viable measure to evaluate and validate the assumption of the micropore constitutive equation. Manca et al. [29] conducted MIP test to determine the macropore $(r>1 \mu \mathrm{m})$ void ratio for bentonite under permeation of $4 \mathrm{M}$ saline at $e^{\mathrm{M}}=0.35$ for $e_{0}=0.78$, corresponding to the portion of microporosity $f_{\mathrm{m}}=0.55$. The osmotic suction of $4 \mathrm{M} \mathrm{NaCl}$ solution is reported as $\pi=22.5 \mathrm{MPa}$ [26]. This leads to a calculated $w=0.16$ from the WRC (Fig. 6). Then the micropore void ratio is given as $e_{\mathrm{m}}=2.9 * 0.16=0.464$, where the ratio 2.9 is the average of 2.75 and 3.08 for DI and brine solution, respectively. This corresponds to the portion of microporosity $f_{\mathrm{m}}=0.59$ and is close to the experimental results of $f_{\mathrm{m}}=0.55$ (7\% variance error). Therefore, the proposed model is an acceptable approximate that can correlate the microporosity with water content.

Using this formula, we can analyse the double-porosity proportion by the water content and suction level for any bentonite samples. For instance, the initial condition of the as-compacted bentonite specimen (by Queen's University) is $w_{0}=0.11, \rho_{\mathrm{d}}=1.6 \mathrm{~g} / \mathrm{cm}^{3}$, which indicates $e_{\mathrm{m}}=0.3$. and $f_{\mathrm{m}}=0.42$. When saturated with brine, the osmotic suction level of $40 \mathrm{MPa}$ corresponds to a gravimetric water content of 0.15 . At a dry density of $1 \mathrm{~g} / \mathrm{cm}^{3}$, this results in a micropore void ratio $e_{\mathrm{m}}=3.08 \mathrm{w}$ and the portion of microporosity $f_{\mathrm{m}}=0.643$, which is much less than 1.0 , suggesting a significant portion of macropore even at full saturation.

\subsection{Finite element model for constant volume swelling test}

The following governing equations of the model are implemented and solved in COMSOL (V 5.3).

$$
\begin{aligned}
& \nabla \cdot \sigma=0 \\
& n^{\mathrm{m}} \frac{\partial C^{\mathrm{m}}}{\partial t}=\nabla D_{\mathrm{e}} \nabla C^{\mathrm{m}}-(1-\omega) \nabla\left(v^{\mathrm{m}} C^{\mathrm{m}}\right) \\
& \quad+Q_{\mathrm{c}}^{\mathrm{m}}-C^{\mathrm{m}} \frac{\partial \varepsilon_{\mathrm{v}}}{\partial t} \\
& n^{\mathrm{M}} S_{\mathrm{e}}^{\mathrm{M}} \frac{\partial C^{\mathrm{M}}}{\partial t}=D_{0} \nabla^{2} C^{\mathrm{M}}-\nabla\left(v^{\mathrm{M}} C^{\mathrm{M}}\right) \\
& \quad+Q_{\mathrm{c}}^{\mathrm{M}}-C^{\mathrm{M}} n^{\mathrm{M}} \frac{\partial S_{\mathrm{e}}^{\mathrm{M}}}{\partial t} \\
& \frac{\partial}{\partial t}\left(\rho_{l} n^{\mathrm{m}}\right)-\nabla \frac{k_{\mathrm{s}}^{\mathrm{m}}}{\mu} \rho_{l}\left(\nabla p^{\mathrm{m}}-k_{\mathrm{c}} \nabla C^{\mathrm{m}}\right)=Q_{\mathrm{m}} \\
& G_{\mathrm{s}} \rho_{l} w^{\mathrm{M}}\left(C_{\mathrm{m}} \frac{\partial p^{\mathrm{M}}}{\partial t}+C_{\mathrm{s}} \frac{\partial C^{\mathrm{M}}}{\partial t}\right) \\
& \quad-\nabla \frac{k_{\mathrm{s}}^{\mathrm{M}} k_{\mathrm{r}}}{\mu} \rho_{l}\left(\nabla p^{\mathrm{M}}-k_{\mathrm{c}} \nabla C^{\mathrm{M}}\right)=-G_{\mathrm{s}} \rho_{l} w \frac{\partial \varepsilon_{\mathrm{v}}^{\mathrm{M}}}{\partial t}+Q_{\mathrm{M}}
\end{aligned}
$$

where the storage terms are given as $C_{\mathrm{m}}=\left(1-n^{\mathrm{M}}\right)$ $\left(\chi_{\mathrm{f}}+\frac{B}{p^{\mathrm{M}} w^{\mathrm{M}}}\right)-n^{\mathrm{M}} \chi_{\mathrm{s}}$ and $C_{\mathrm{s}}=n^{\mathrm{M}} \chi_{\mathrm{s}} k_{\mathrm{c}}+\left(1-n^{\mathrm{M}}\right) \frac{k_{2}}{\rho_{l}}$.

Table 1 shows the input parameters. Extensive simulation trials have been carried out to determine an appropriate range for these input parameters. The parameters shown are to the ones that best reproduce the experimental data. 
Table 1 Model input parameters

\begin{tabular}{|c|c|c|c|}
\hline \multirow[t]{2}{*}{ Variable } & \multirow[t]{2}{*}{ Unit } & \multicolumn{2}{|l|}{ Value/expression } \\
\hline & & $\begin{array}{l}\text { Validation A } \\
\text { (Posiva data) }\end{array}$ & $\begin{array}{l}\text { Validation B } \\
\text { (Queen's U data) }\end{array}$ \\
\hline \multicolumn{4}{|c|}{ Initial conditions } \\
\hline$G_{\mathrm{s}}$ & & 2.75 & 2.75 \\
\hline$\rho_{\mathrm{d}}$ & & 1.7 & 1.6 \\
\hline$e_{0}$ & & $G_{\mathrm{s}} / 1.7-1$ & $G_{\mathrm{s}} / 1.6-1$ \\
\hline$w_{0}$ & & 0.05 & 0.11 \\
\hline$e_{\mathrm{m}}$ & & Equation (6) & Equation (6) \\
\hline \multicolumn{4}{|c|}{ Saturated permeability } \\
\hline$k_{\mathrm{s}}^{\mathrm{M}}$ & $\mathrm{m} / \mathrm{s}$ & $4 * k^{\mathrm{m}}$ & Equations (7-8) \\
\hline$k_{\mathrm{s}}^{\mathrm{M}}$ & $\mathrm{m} / \mathrm{s}$ & $2 *$ Equation $(5)$ & Equation (5) \\
\hline \multicolumn{4}{|c|}{ Relative permeability } \\
\hline$k_{\mathrm{r}}^{\mathrm{m}}$ & & $S_{\mathrm{e}}^{3}$ & 1 \\
\hline$k_{\mathrm{r}}^{\mathrm{m}}$ & & $(0.8)^{6}$ & 1 \\
\hline \multicolumn{4}{|c|}{ Chemo-osmosis } \\
\hline$\omega$ & & - & $0.97-0.98$ \\
\hline$k_{\mathrm{c}}$ & $\mathrm{Pa} \mathrm{m} 3 / \mathrm{mol}$ & - & $8.83 \mathrm{E} 3$ \\
\hline \multicolumn{4}{|c|}{$\begin{array}{l}\text { Mass } \\
\text { exchange }\end{array}$} \\
\hline $\bar{\alpha}$ & $\mathrm{m} / \mathrm{Pa} \mathrm{s}$ & $2 * k^{\mathrm{m}} * \rho_{l}$ & $10 * k^{\mathrm{m}} * \rho_{l}$ \\
\hline$D_{\mathrm{e}}$ & $\mathrm{m}^{2} / \mathrm{s}$ & - & Equation (12) \\
\hline$L_{\mathrm{c}}$ & $\mathrm{m}$ & - & $1 \mathrm{E}-5$ \\
\hline $\bar{D}$ & $\mathrm{~m} / \mathrm{s}$ & - & Equation (50) \\
\hline$H$ & $\mathrm{~m}^{3} / \mathrm{mol}$ & - & $0.004-0.005$ \\
\hline$Q^{\mathrm{M}}$ & $\mathrm{m} / \mathrm{s}$ & - & Equation (45) \\
\hline \multicolumn{4}{|c|}{ Solute transport } \\
\hline$D_{0}$ & $\mathrm{~m}^{2} / \mathrm{s}$ & - & $1 \mathrm{E}-9$ \\
\hline$\tau^{\mathrm{m}}$ & - & - & $D_{0} /$ Eq. (12) \\
\hline$\tau^{\mathrm{M}}$ & - & - & 1 \\
\hline \multicolumn{4}{|c|}{ Water retention curve } \\
\hline$S_{\mathrm{u}}^{\mathrm{m}}$ & $\mathrm{Pa}$ & From Eq. (14) & From Eq. (14) \\
\hline$S_{\mathrm{ut}}$ & $\mathrm{Pa}$ & 2800 & Equation (15) \\
\hline$S_{\mathrm{u}}^{\mathrm{M}}$ & $\mathrm{Pa}$ & From Eq. (13) & From Eq. (13) \\
\hline \multicolumn{4}{|c|}{ Mechanical property } \\
\hline K & $\mathrm{MPa}$ & 36.4 & $\begin{array}{l}19.3 \text { (DI) } 19.3 \\
\text { (MW) }\end{array}$ \\
\hline \multicolumn{4}{|c|}{$\begin{array}{l}\text { Boundary } \\
\text { condition }\end{array}$} \\
\hline $\mathbb{L}$ & $\mathrm{m} / \mathrm{s}$ & $0.5 \mathrm{E} 7 * k^{\mathrm{M}}$ & $0.5 \mathrm{E} 7 * k^{\mathrm{M}}$ \\
\hline$P_{\text {in }}$ & $\mathrm{MPa}$ & 2 & 0.015 \\
\hline$C_{\text {in }}$ & $\mathrm{M}$ & 0 & 4.6 \\
\hline \multicolumn{4}{|c|}{ Dimension } \\
\hline Radius & $\mathrm{mm}$ & 25 & 19 \\
\hline Height & $\mathrm{mm}$ & 65 & 12 \\
\hline
\end{tabular}

$C$ is chemical concentration in $\left(\mathrm{mol} / \mathrm{m}^{3}\right)$
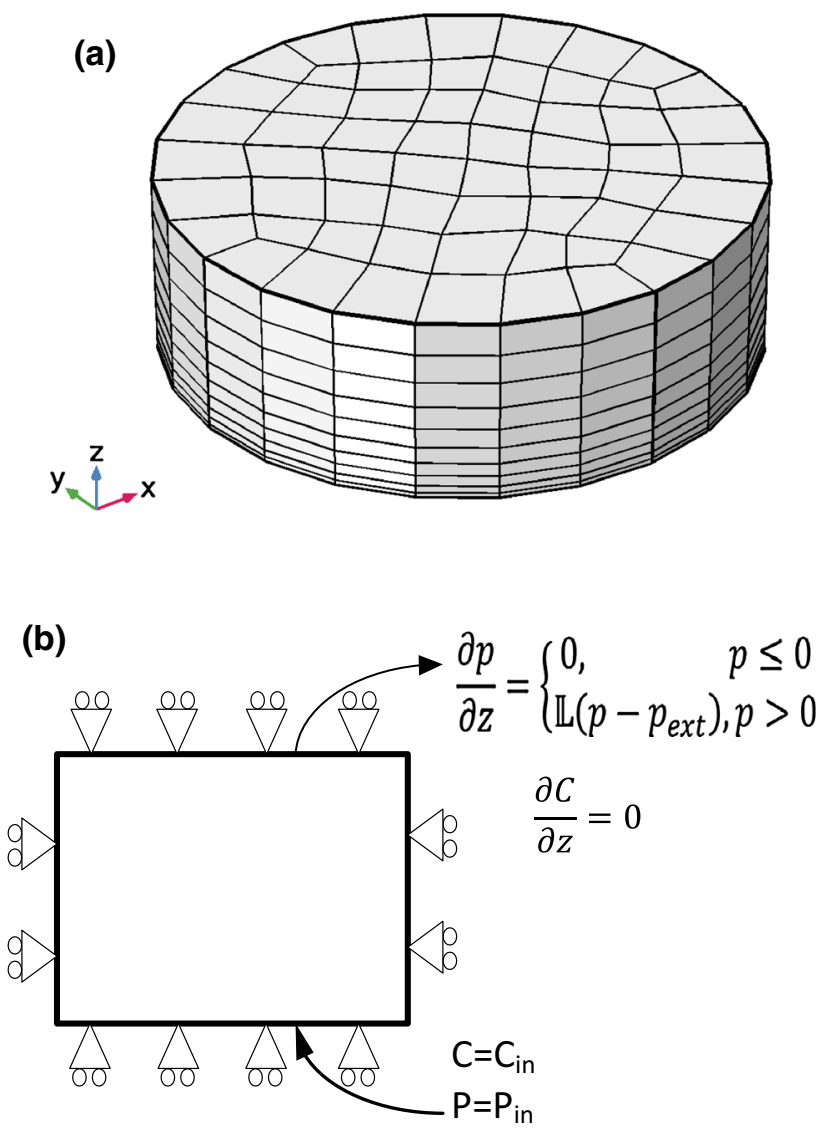

Fig. 9 FEM model for the constant volume swelling test (a) and hydraulic-mechanical-chemical boundary conditions (b)

Figure 9 shows the finite element discretization and boundary conditions of the compacted bentonite specimen infiltrated with either DI water (Posiva test) or brine (Queen's University test). The bottom boundary is connected to the supply of permeant at constant pressure, while the top boundary is left open to ambient atmospheric pressure prior to flow through. Once pore fluid penetrates through the specimen, the top boundary is maintained as highly permeable and well drained to avoid water pressure build-up. This is a mixed Robin-type boundary condition given as

$\frac{\partial p}{\partial z}= \begin{cases}0, & p \leq 0 \\ L\left(p-p_{\text {ext }}\right), & p>0\end{cases}$

where $\mathbb{L}$ is a flow transfer coefficient shown in Table $1, p_{\text {ext }}$ is the target pressure ( $0 \mathrm{MPa}$ in this work). The side wall is as assumed to be impermeable. The bottom boundary is kept at a constant chemical concentration equal to the one of the brine inflow. The top end is Neumann-type boundary for solute transport. 


\subsection{Simulation of Posiva test}

This case addressed the experimental results of Posiva THM-coupled investigations, from a single series of test data (\#100416) reported by Pintado et al. [40]. As a first step of validation of the HM coupling, the data on infiltration of low salinity water through MX-80 bentonite column were selected for analysis and modelling. A compacted MX-80 bentonite column with dry density at $1.7 \mathrm{~g} /$ $\mathrm{cm}^{3}$ and initial water content of about $5 \%$ was infiltrated with low salinity water (salinity $0.87 \mathrm{~g} / \mathrm{L}$ ). The pressure head was maintained at $2 \mathrm{MPa}$ for the inlet, while the outlet was open to ambient atmospheric pressure. The specimen has a diameter of $5 \mathrm{~cm}$ and a height of $6.3 \mathrm{~cm}$. Figure 10 shows the sketch of the test and the instrumentation.

Due to the very low salinity of the permeant, the modelling ignored the effect of pore fluid chemistry and considered mainly the interaction between macropores and micropores. As shown in Table 1, most of the model parameters are the same as what we derived theoretically for MX-80 bentonite. These include the micropore void ratio and the water retention curves for both the micropore and macropore. Only minor adjustments were made with respect to the permeability and unsaturated state variables

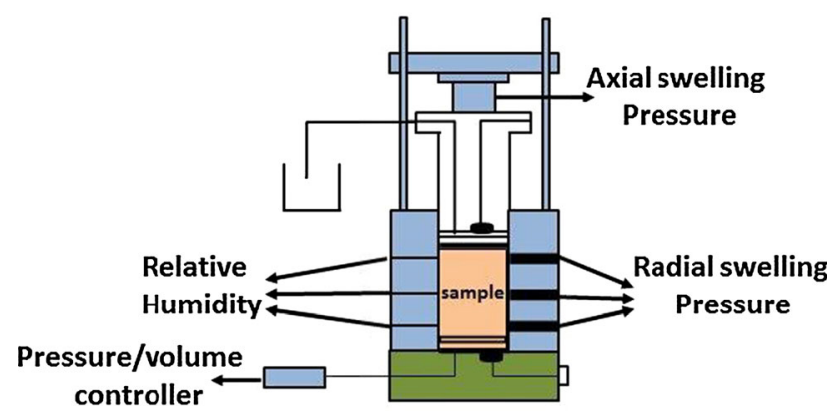

Fig. 10 Schematic diagram of the Posiva infiltration test set-up [40]

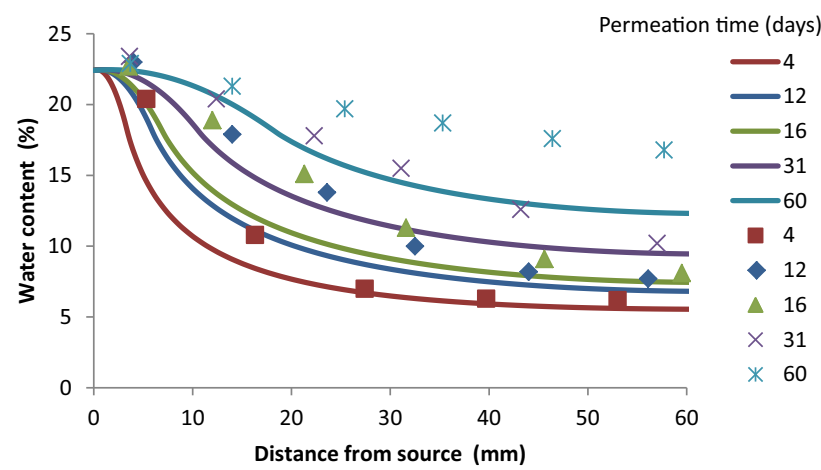

Fig. 11 Posiva test: distribution of water content at various permeation time (days) - the modelling results (solid lines) are compared with the experimental data (dots)
Figures 11, 12, 13 and 14 show the modelling results and the comparison with experimental data in terms of water content profile, suction profile, inflow volume and measured swelling pressure. It can be seen from those figures that the water infiltration volume and the suction profile are both well reproduced. The modelled swelling pressure compares well with the measured value, both in trend and magnitude. Although a discrepancy is found in the water content profile, the movement of the water front from the inlet towards the outlet is consistent with the experimental results. This is likely due to the variability in WRC, as the water content is computed on the basis of the water retention curve. It is shown that the total volume of water injection at the end of test after 2 months remains very small compared to the total volume of the soil specimen ( $32 \mathrm{~mL}$ vs. $124 \mathrm{~mL}$ ), indicating a very low permeability in the specimen. Using a bulk modulus $(K=36.4 \mathrm{MPa})$ in the model is found to result in a satisfying prediction of the swelling pressure. However, the oedometer measurement $(K=43.5 \mathrm{MPa})$ is somewhat higher than the modelling input.

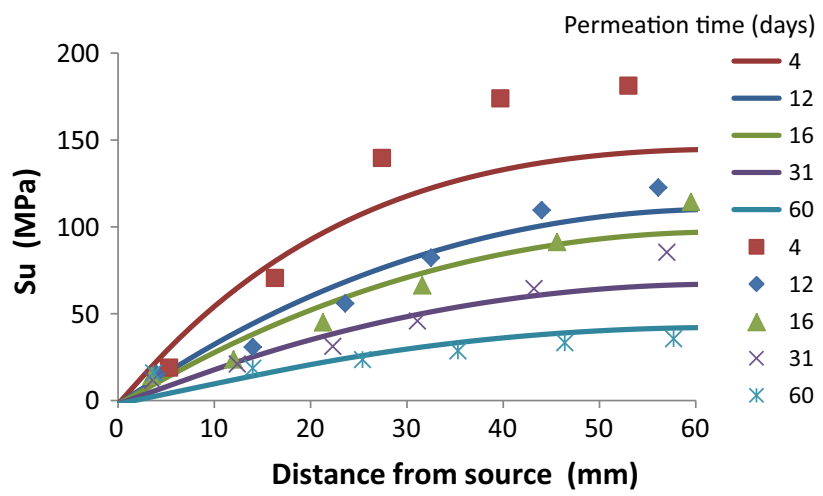

Fig. 12 Posiva test: distribution of matric suction at various permeation time (days) - the modelling results (solid lines) are compared with the experimental data (dots)

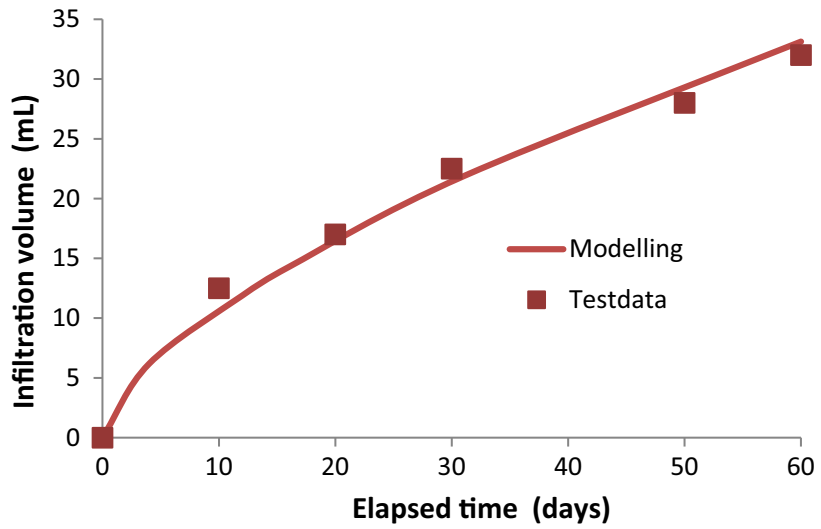

Fig. 13 Posiva test: variation of inflow volume with elapsed permeation period of time (days) 


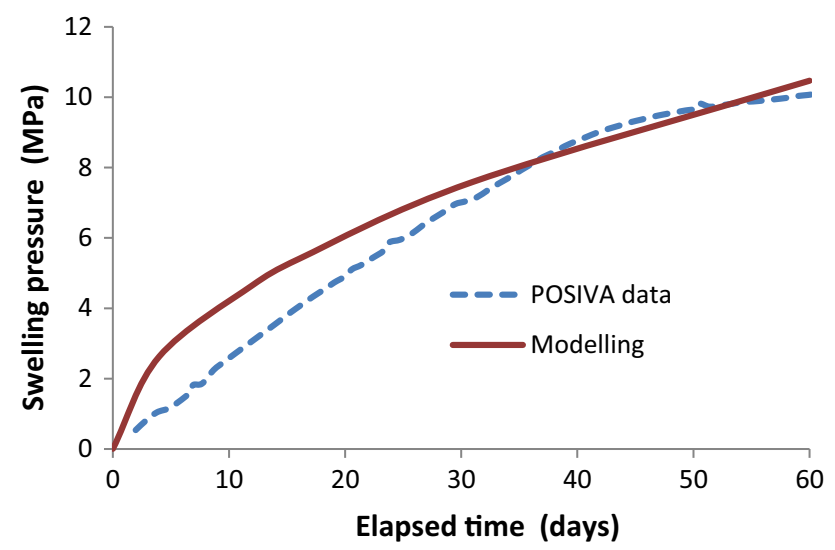

Fig. 14 Posiva test: the measured and modelled temporal variation of swelling pressure

\subsection{Simulation of Queen's University tests}

\subsubsection{Experimental results of temporal variation of swelling pressure}

The CNSC initiated a collaborative research with Queen's University to study the chemical influences on swelling behaviours of MX-80 bentonite under various dry densities with permeation of two types of pore fluid, i.e. DI water and MW (highly concentrated brine). The MW has a molarity of $4.6 \mathrm{M}$ and is mainly composed of $\mathrm{NaCl}, \mathrm{KCl}$, $\mathrm{CaCl}_{2}$ and $\mathrm{MgSO}_{4}$. Both bentonite and sand/bentonite mixture were investigated. The experimental results for the variation of swelling pressure under constant volume conditions are presented in Fig. 15. Table 2 provides a summary description of the tests with their acronyms.

Pore fluid chemistry has a significant impact on the swelling of bentonite as shown in Fig. 15. With the same dry density, DI water infiltration results in a peak swelling pressure about three times higher than the MW case. Within $500 \mathrm{~h}$, no obvious variation in swelling pressure for the case of DI water can be noticed from the test data. After $500 \mathrm{~h}$, the swelling pressure gradually decreases and reached a stable value by $2000 \mathrm{~h}$ for DI water, while for $\mathrm{MW}$, the swelling pressure took much longer to stabilize after $8000 \mathrm{~h}$ of continuous permeation. The swelling pressure for DI water decreases by approximately $10 \%$ from the peak, whereas for MW, a decrease of $80-90 \%$ from the peak was observed. Sand-bentonite mixtures (SB) show a very similar swelling behaviour with bentonite with the same value in EMDD. Our modelling efforts will focus on reproducing the gradual decrease in swelling pressure under hydration of brine water.

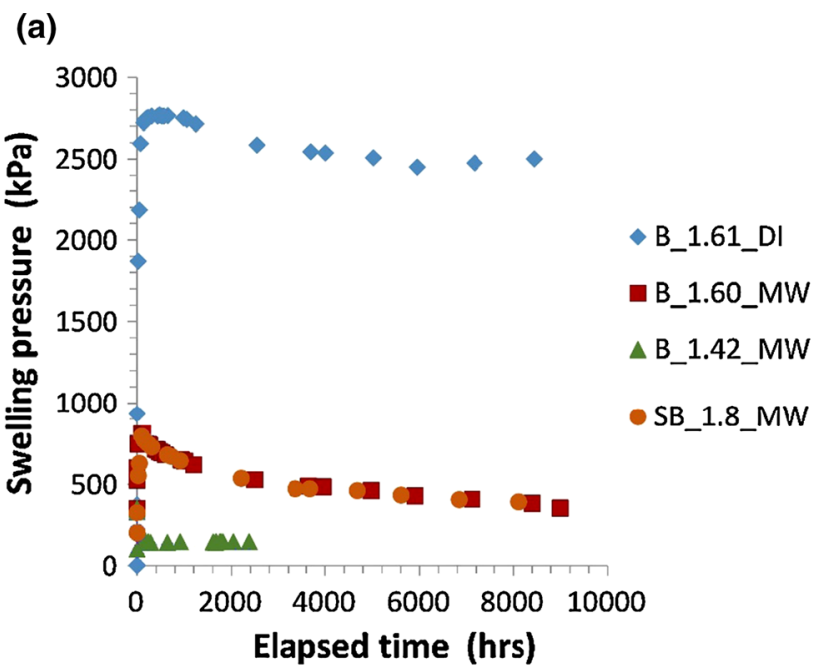

(b)

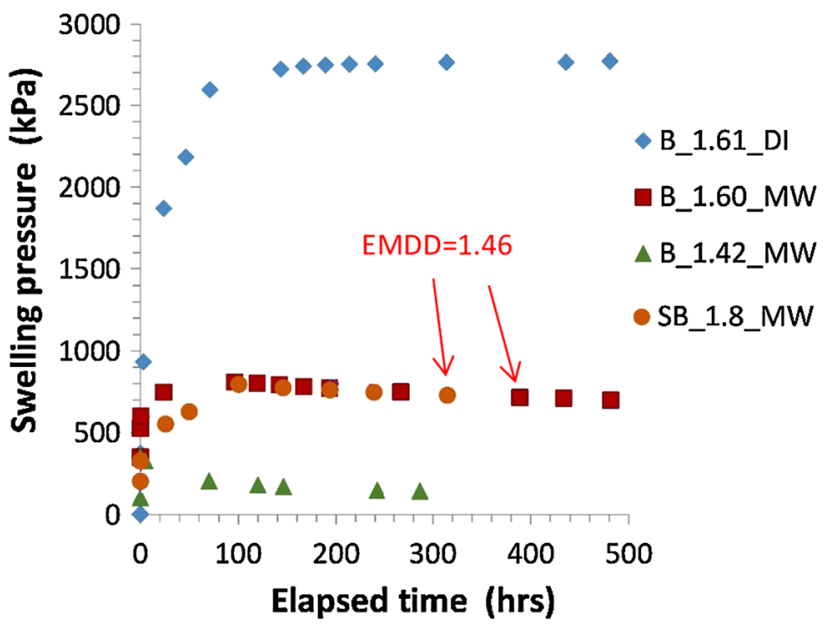

Fig. 15 Variation of swelling pressure with elapsed time for MX-80 at different dry densities and pore fluid scenarios a long-term behaviour and b short-term behaviour [42]

Table 2 Experimental conditions for Queen's University dataset

\begin{tabular}{|c|c|c|c|}
\hline Sample ID & $\begin{array}{l}\text { Soil } \\
\text { composition }\end{array}$ & $\begin{array}{l}\text { Dry density }(\mathrm{g} / \\
\left.\mathrm{cm}^{3}\right)\end{array}$ & Permeant \\
\hline B_1.61_DI & $\begin{array}{c}\text { Bentonite } \\
\text { MX-80 }\end{array}$ & 1.61 & DI water \\
\hline B_1.60_MW & $\begin{array}{c}\text { Bentonite } \\
\text { MX-80 }\end{array}$ & 1.60 & $\begin{array}{l}\text { Model water } \\
\text { (brine) }\end{array}$ \\
\hline B_1.42_MW & $\begin{array}{c}\text { Bentonite } \\
\text { MX-80 }\end{array}$ & 1.42 & $\begin{array}{l}\text { Model water } \\
\text { (brine) }\end{array}$ \\
\hline SB_1.8_MW & $\begin{array}{l}\text { Bentonite } 70 \% \\
\text { Sand } 30 \%\end{array}$ & 1.80 & $\begin{array}{l}\text { Model water } \\
\text { (brine) }\end{array}$ \\
\hline
\end{tabular}




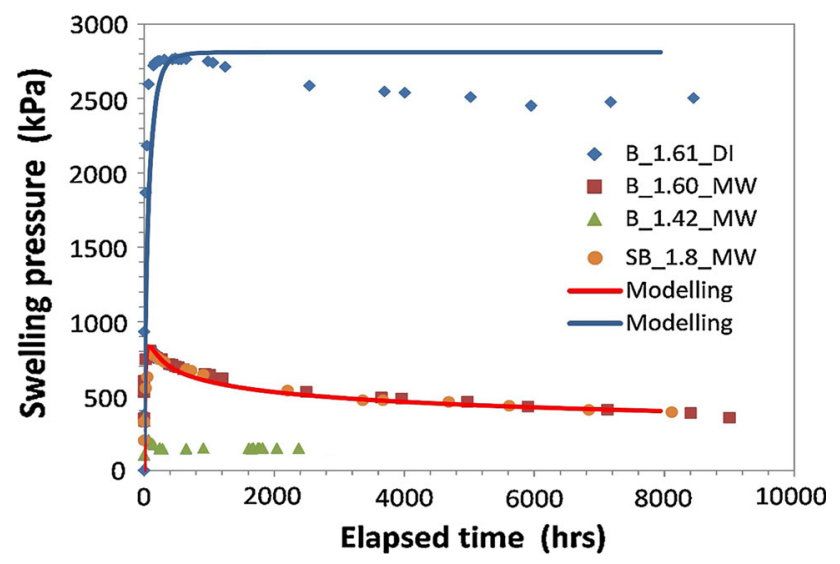

Fig. 16 Temporal variation of swelling pressure of MX-80 bentonite under permeation of DI water and brine

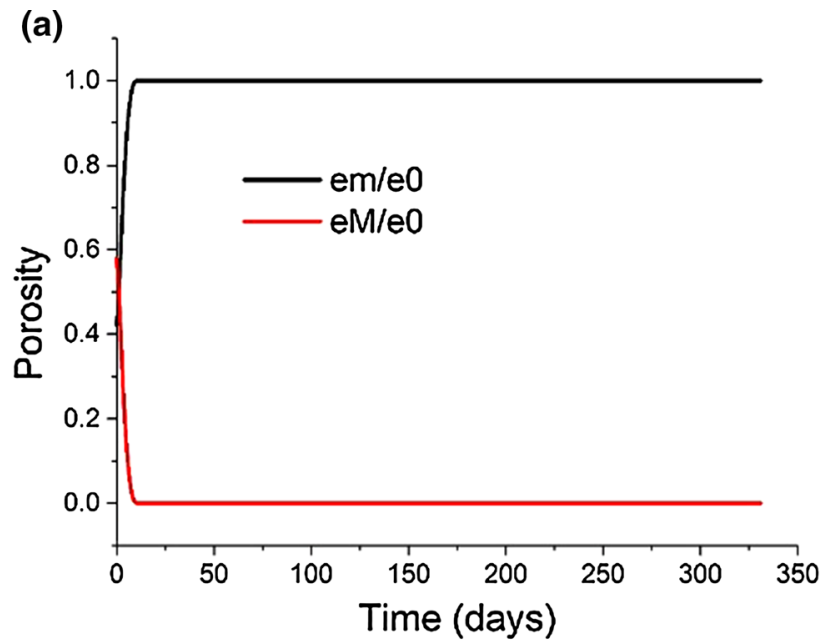

(c)

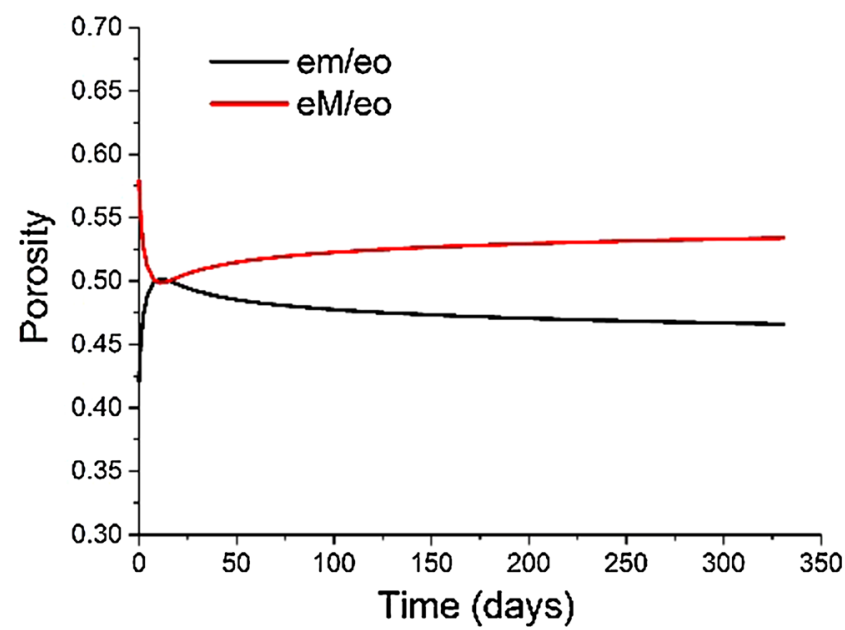

\subsubsection{Modelled temporal variation of swelling pressure}

Figure 16 compares the modelling and measured results for swelling pressure. It is shown that the model simulates very well the pressure transient. Consistent with the experimental data, the model was able to reproduce the substantial long-term decrease in swelling pressure in the MW case. The model also shows that a much higher swelling pressure was developed for the DI water case, at early time, and did not decrease in the long term. The experimental data show, however, a decay of swelling pressure even for the DI case, although it is less pronounced as in the MW case. It is believed that this is due to a redistribution of chemicals like sodium ions between the double-porosity structures. Sodium ions are originally present in MX-80 bentonite crystalline structures predominantly in the

(b)

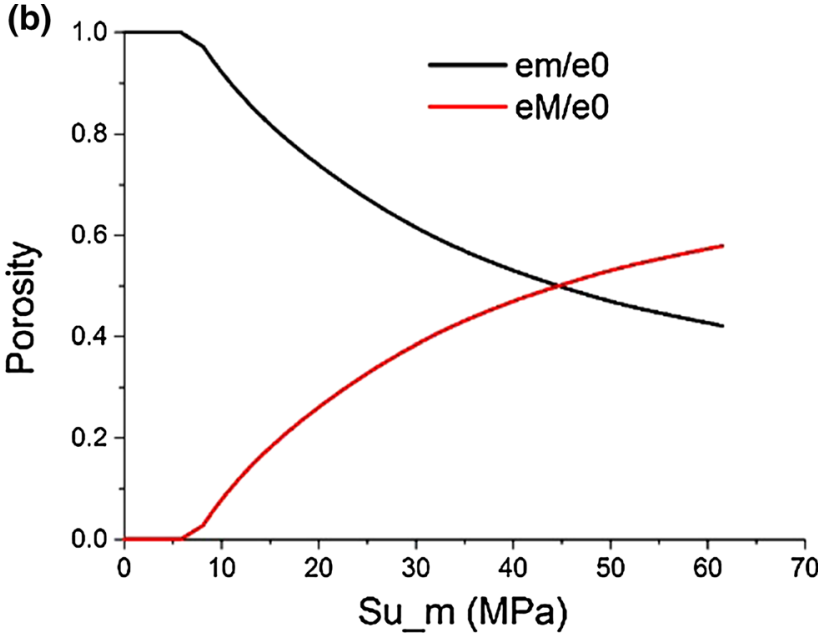

(d)

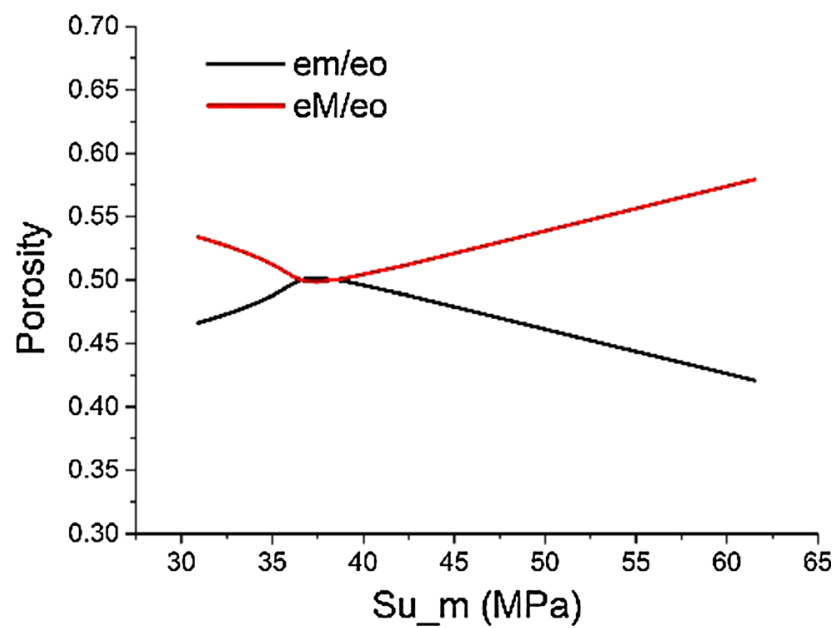

Fig. 17 Variation of pore fractions with time and matric suction for bentonite permeated with DI water (a, b) and brine solution (c, d) 

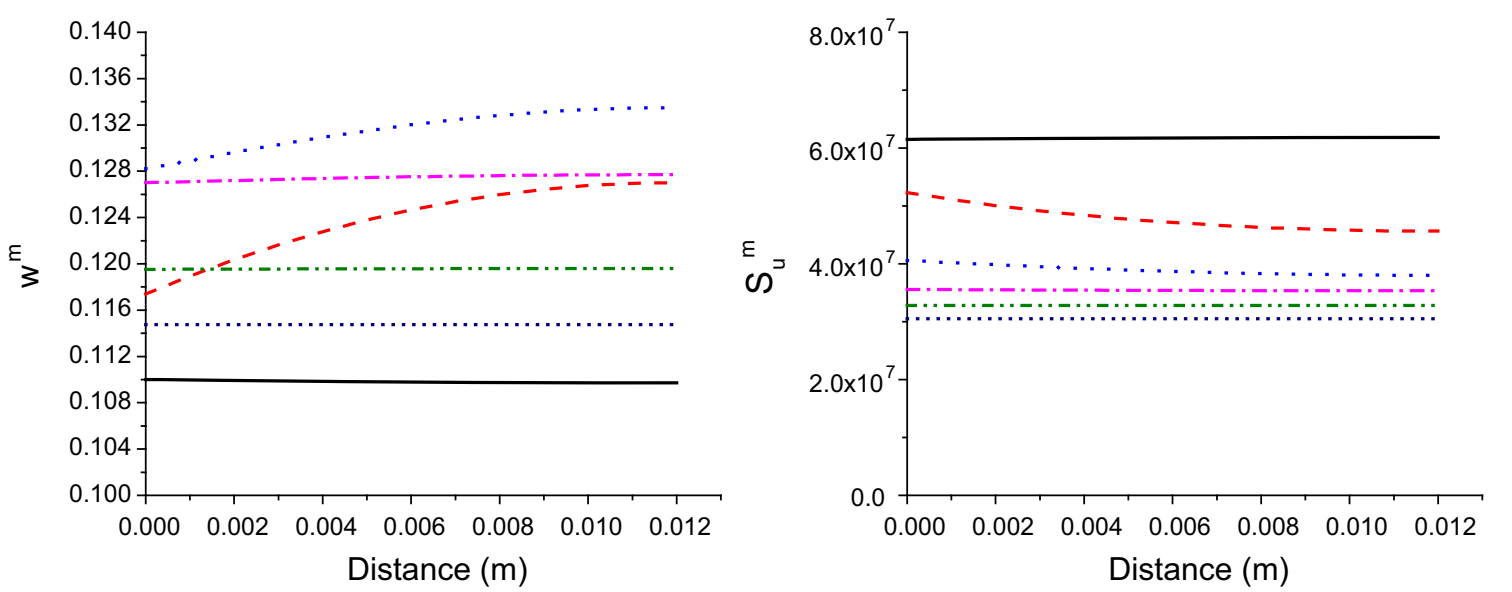

Time (hrs)

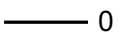

$---\cdot 20$
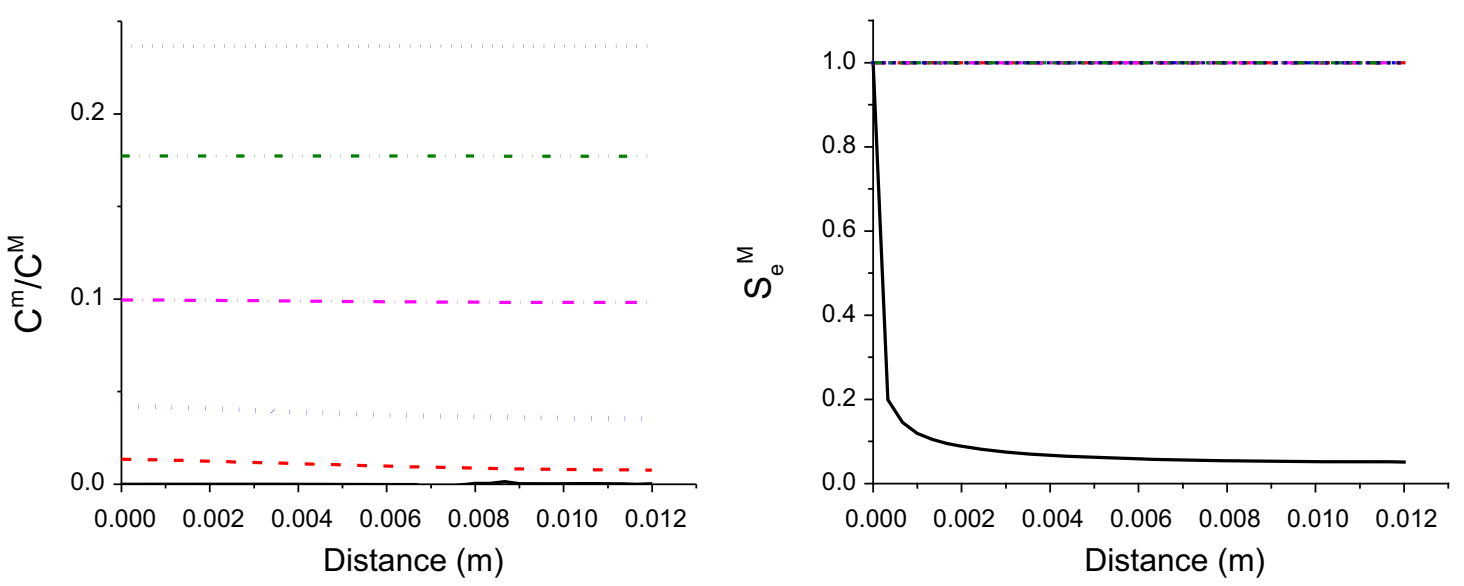

$\cdots \cdot 100$

$-\cdot-\cdot-500$

$-\cdots-\cdots-2500$

........ 8000

Fig. 18 Variation of parameters with change in distance from inlet for the permeation of brine solution

micropores, but later migrate into the macropore space and reducing the balance of osmotic suction between the two pore types. Using the current theoretical framework, this phenomenon can be further investigated in order to provide better understanding and quantification. This will be the subject of future investigations.

Figure 17a-d shows the modelled results for variation of microporosity and macroporosity with time and suction. The micropore fraction is found to increase generally with decrease in suction. The brine solution substantially suppresses the expansion of micropores, with a much smaller growth rate in wetting stage compared to DI water. The trend of micropore variation is consistent with the experimental observation of the swelling pressure.

Figure 18 shows the modelled profile of several variables at different permeation periods. The macropore reaches full saturation within a few days. In the meanwhile, micropore water content and matric suction is still changing. Mass exchange between the two pore structures leads to a gradual increase of micropore salinity, which remains lower than that of the macropore for the whole simulation period.
Figure 18 gives a brief illustration of the overall HMCcoupled processes occurring in MX-80 bentonite under permeation of brine. It is shown that the micropore water content $w^{\mathrm{m}}$ varies significantly with time at different locations. At $100 \mathrm{~h}$, the modelled $w^{\mathrm{m}}$ reaches a peak value at regions close to the outlet boundary, where $e^{\mathrm{M}}$ remains in a low level before the chemical front passes that point. In the beginning, the macropore becomes saturated quickly, while chemical transport therein is delayed compared to the water movement due to chemical exchange with the micropore. In regions further away from the inlet, water would be preferentially absorbed into the micropore because of the lack of osmotic suction gradient. The swelling pressure peak may be correlated with the chemical front in the macropore. The extremely concentrated brine poses a very high osmotic suction on the clay aggregate that draws water from the micropore, causing a decrease of the microporosity and then a decline of the swelling pressure. This observation corresponds well to the conceptual model and seems well justified. 


\section{Conclusion}

In this study, a HMC-coupled model was developed for compacted unsaturated bentonite. The model is based on a dual-porosity framework and considers the effect of salinity on various hydraulic and mechanical properties. A series of relationships for HMC properties have been proposed for MX-80 bentonite. Effective approaches to estimate the WRC and hydraulic conductivity for each porosity component were proposed and verified. The coupled HMC model was used to simulate laboratory swelling experiments on compacted MX-80 bentonite specimens infiltrated with DI water and brine, respectively. A good agreement between the model results and the experimental data, both in trends and absolute values, suggest that the main processes have been captured.

Many of the parameters representive of the hydraulicchemical characteristics of the bentonite are derived by best-fit correlations of available data from the literature combined with the ones determined from laboratory tests at Queen's University. Despite the variability of the data sources, these empirical correlations when used as input to the proposed model are able to reproduce the main processes found from swelling tests performed at two different laboratories. Further in-depth microporosimetric studies, as part of CNSC's ongoing regulatory research, are being conducted at Queen's University in order to verify, calibrate and further refine the current model and improve our understanding of the effects of salinity on the swelling potential of bentonite.

Open Access This article is distributed under the terms of the Creative Commons Attribution 4.0 International License (http://creative commons.org/licenses/by/4.0/), which permits unrestricted use, distribution, and reproduction in any medium, provided you give appropriate credit to the original author(s) and the source, provide a link to the Creative Commons license, and indicate if changes were made.

\section{References}

1. Agus SS, Arifin YF, Tripathy S, Schanz T (2013) Swelling pressure-suction relationship of heavily compacted bentonitesand mixtures. Acta Geotech 8(2):155-165. https://doi.org/10. 1007/s11440-012-0189-0

2. Akesson M, Jacinto AC, Gatabin C, Sanchez M, Ledesma A (2009) Bentonite THM behaviour at high temperatures: experimental and numerical analysis. Geotechnique 59(4):307-318. https://doi.org/10.1680/geot.2009.59.4.307

3. Alonso EE, Romero E, Hoffmann C (2011) Hydromechanical behaviour of compacted granular expansive mixtures: experimental and constitutive study. Geotechnique 61(4):329-344. https://doi.org/10.1680/geot.2011.61.4.329

4. Bourg IC, Sposito G, Bourg ACM (2007) Modeling cation diffusion in compacted water-saturated Na-bentonite at low ionic strength. Environ Sci Technol 41(23):8118-8122
5. Bradbury MH, Baeyens B (2011) Physico-Chemical Characterisation Data and Sorption Measurements of $\mathrm{Cs}, \mathrm{Ni}, \mathrm{Eu}, \mathrm{Th}, \mathrm{U}, \mathrm{Cl}$, I and Se on MX-80 Bentonite. Nucl Energy Saf Res Dep Lab Waste Manag. ISSN 1019-0643

6. Carmen PC (1938) The determination of the specific surface of powders. J Soc Chem Ind Trans 57:225

7. Carrier WD III (2003) Goodbye, Hazen; hello, Kozeny-Carman. J Geotech Geoenviron Eng 129(11):1054-1056. https://doi.org/ 10.1061/(ASCE)1090-0241(2003)129:11(1054)

8. Della Vecchia G, Musso G (2016) Some remarks on single- and double-porosity modeling of coupled chemo-hydro-mechanical processes in clays. Soils Found 56(5):779-789. https://doi.org/10. 1016/j.sandf.2016.08.004

9. Dieudonne AC, Gatabin C, Talandier J, Collin F, Charlier R (2016) Water retention behaviour of compacted bentonites: experimental observations and constitutive model. In: Delage P, Cui YJ, Ghabezloo S, Pereira JM, Tang AM (eds) E3S Web of conferences 3rd European conference on unsaturated soils-EUnsat 2016, vol 9. https://doi.org/10.1051/e3sconf/20160911012

10. Dieudonne A-C, Della Vecchia G, Charlier R (2017) Water retention model for compacted bentonites. Can Geotech J 54(7):915-925. https://doi.org/10.1139/cgj-2016-0297

11. Dixon DA, Man A, Stone J, Rimal S, Siemens G, Abootalebi P, Birch K (2016) Backfilling and sealing materials for a deep geological repository. In: 3rd Canadian conference on nuclear waste management, decommissioning and environmental restoration, Ottawa, ON, Canada

12. Do Guimarães LN, Gens A, Sánchez M, Olivella S (2013) A chemo-mechanical constitutive model accounting for cation exchange in expansive clays. Geotechnique 63(3):221-234

13. Fernandez AM, Villar MV (2010) Geochemical behaviour of a bentonite barrier in the laboratory after up to 8 years of heating and hydration. Appl Geochem 25(6):809-824. https://doi.org/10. 1016/j.apgeochem.2010.03.001

14. Fredlund DG, Rahardjo H, Fredlund MD (2012) Unsaturated soil mechanics in engineering practice. Wiley, Hoboken

15. Gens A, Sanchez M, Guimaraes LDN, Alonso EE, Lloret A, Olivella S, Villar MV, Huertas F (2009) A full-scale in situ heating test for high-level nuclear waste disposal: observations, analysis and interpretation. Geotechnique 59(4):377-399. https:// doi.org/10.1680/geot.2009.59.4.377

16. Gens A, Guimaraes LDN, Sanchez M, Vallejan B (2011) Coupled analysis of double porosity swelling clays. In: Borja RI (ed) Multiscale and multiphysics processes in geomechanics: results of the workshop on multiscale and multiphysics processes in geomechanics. Springer, Berlin, pp 85-88

17. Gens A, Vallejan B, Sanchez M, Imbert C, Villar MV, Van Geet M (2011) Hydromechanical behaviour of a heterogeneous compacted soil: experimental observations and modelling. Geotechnique 61(5):367-386. https://doi.org/10.1680/geot.SIP11.P.015

18. Herbert HJ, Kasbohm J, Sprenger H, Fernández AM, Reichelt C (2008) Swelling pressures of MX-80 bentonite in solutions of different ionic strength. Phys Chem Earth 33(SUPPL. 1):S327S342. https://doi.org/10.1016/j.pce.2008.10.005

19. Hoffmann C, Alonso EE, Romero E (2007) Hydro-mechanical behaviour of bentonite pellet mixtures. Phys Chem Earth 32(8-14):832-849. https://doi.org/10.1016/j.pce.2006.04.037

20. Jo HY, Katsumi T, Benson CH, Edil TB (2001) Hydraulic conductivity and swelling of nonprehydrated GCLs permeated with single-species salt solutions. J Geotech Geoenviron Eng 127:557-567

21. Keijzer TJS, Kleingeld PJ, Loch JPG (1999) Chemical osmosis in compacted clayey material and the prediction of water transport. Eng Geol 53(2):151-159. https://doi.org/10.1016/s00137952(99)00028-9 
22. Kozeny J (1927) Ueber kapillare Leitung des Wassers im Boden. Wien, Akad Wiss 136(2a):271

23. Krahn J, Fredlund DG (1972) On total, matric and osmotic suction. Soil Sci 114(5):339-348

24. Li Z, Katsumi T, Inui $\mathrm{T}$, Takai A (2013) Fabric effect on hydraulic conductivity of kaolin under different chemical and biochemical conditions. Soils Found 53(5):680-691. https://doi. org/10.1016/j.sandf.2013.08.006

25. Li Z, Xue Q, Katsumi T, Inui T (2014) Electric-hydraulicchemical coupled modeling of solute transport through landfill clay liners. Appl Clay Sci 101:541-552

26. Luo Y, Roux B (2010) Simulation of osmotic pressure in concentrated aqueous salt solutions. J Phys Chem Lett 1(1):183-189. https://doi.org/10.1021/jz900079w

27. Malusis MA, Shackelford CD (2002) Chemico-osmotic efficiency of a geosynthetic clay liner. J Geotech Geoenviron Eng 128(2):97-106. https://doi.org/10.1061/(asce)1090-0241(2002) 128:2(97)

28. Man A, Martino JB (2009) Thermal, hydraulic and mechanical properties of sealing materials. NWMO, Toronto

29. Manca D, Ferrari A, Laloui L (2016) Fabric evolution and the related swelling behaviour of a sand/bentonite mixture upon hydro-chemo-mechanical loadings. Geotechnique 66:41-57. https://doi.org/10.1680/jgeot.15.P.073

30. Melkior T, Gaucher EC, Brouard C, Yahiaoui S, Thoby D, Clinard C, Ferrage E, Guyonnet D, Tournassat C, Coelho D (2009) $\mathrm{Na}+$ and HTO diffusion in compacted bentonite: effect of surface chemistry and related texture. J Hydrol 370(1-4):9-20. https://doi.org/10.1016/j.jhydrol.2009.02.035

31. Murad MA, Moyne C (2008) A dual-porosity model for ionic solute transport in expansive clays. Comput Geosci 12(1):47-82. https://doi.org/10.1007/s10596-007-9060-z

32. Musso G, Romero Morales E, Gens A, Castellanos E (2003) The role of structure in the chemically induced deformations of FEBEX bentonite. Appl Clay Sci 23(1-4):229-237. https://doi. org/10.1016/S0169-1317(03)00107-8

33. Musso G, Della Vecchia G, Romero E (2013) Modeling the coupled chemo-hydro-mechanical behavior of compacted active clays. In: Manassero M, Dominijanni A, Foti S, Musso G (eds) Coupled phenomena in environmental geotechnics, 1st edn. CRC Press. ISBN 9781138000605

34. Musso G, Romero E, della Vecchia G (2013) Double-structure effects on the chemo-hydro-mechanical behaviour of a compacted active clay. Geotechnique 63(3):206-220

35. Nakashima $\mathrm{Y}$ (2006) $\mathrm{H}_{2} \mathrm{O}$ self-diffusion coefficient of water-rich MX-80 bentonite gels. Clay Miner 41:659-668

36. Nasir O, Nguyen TS, Barnichon JD, Millard A (2017) Simulation of hydromechanical behaviour of bentonite seals for containment of radioactive wastes. Can Geotech J 54(8):1055-1070

37. Navarro V, Alonso EE (2000) Modeling swelling soils for disposal barriers. Comput Geotech 27(1):19-43. https://doi.org/10. 1016/s0266-352x(00)00002-1

38. Navarro V, Asensio L, Yustres A, Pintado X, Alonso J (2013) Volumetric deformability and water mass exchange of bentonite aggregates. Eng Geol 166:152-159. https://doi.org/10.1016/j. enggeo.2013.09.011

39. Navarro V, Asensio L, De la Morena G, Pintado X, Yustres A (2015) Differentiated intra- and inter-aggregate water content models of mx-80 bentonite. Appl Clay Sci 118:325-336

40. Pintado X, Mamunul HM, Martikainen J (2013) Thermo-hydromechanical tests of buffer materials. In: POSIVA 2012-49. POSIVA, Eurajoki
41. Revil A (2017) Transport of water and ions in partially watersaturated porous media. Part 2. Filtration effects. Adv Water Resour 103:139-152. https://doi.org/10.1016/j.advwatres.2016. 07.016

42. Rowe RK, Brachman RWI (2018) Laboratory determination of sealing material performance. Fifth progress report for R613.4. Queen's University, CNSC

43. Rueedi J, Marschall P (2011) Demonstration of gas-permeable seals for radioactive waste repositories-laboratory and in situ experiments. In: Proceedings of the international conference on radioactive waste management and environmental remediation, ICEM. pp 1413-1420. https://doi.org/10.1115/icem2011-59224

44. Salas J, Sena C, Arcos D (2014) Hydrogeochemical evolution of the bentonite buffer in a KBS-3 repository for radioactive waste. Reactive transport modelling of the LOT A2 experiment. Appl Clay Sci 101:521-532. https://doi.org/10.1016/j.clay.2014.09.016

45. Sanchez M, Gens A, Guimaraes LD, Olivella S (2005) A double structure generalized plasticity model for expansive materials. Int J Numer Anal Meth Geomech 29(8):751-787. https://doi.org/10. 1002/nag.434

46. Sanchez M, Gens A, Olivella S (2012) THM analysis of a largescale heating test incorporating material fabric changes. Int $\mathbf{J}$ Numer Anal Meth Geomech 36(4):391-421. https://doi.org/10. 1002/nag.1011

47. Sanchez M, Gens A, Villar MV, Olivella S (2016) Fully coupled thermo-hydro-mechanical double-porosity formulation for unsaturated soils. Int J Geomech. https://doi.org/10.1061/ (asce)gm.1943-5622.0000728

48. Seiphoori A, Ferrari A, Laloui L (2014) Water retention behaviour and microstructural evolution of MX-80 bentonite during wetting and drying cycles. Géotechnique 64(9):721-734. https:// doi.org/10.1680/geot.14.P.017

49. Shokri N, Zhou P, Keshmiri A (2015) Patterns of desiccation cracks in saline bentonite layers. Transp Porous Media 110(2):333-344. https://doi.org/10.1007/s11242-015-0521-x

50. Stewart DI, Studds PG, Cousens TW (2003) The factors controlling the engineering properties of bentonite-enhanced sand. Appl Clay Sci 23(1-4):97-110. https://doi.org/10.1016/s01691317(03)00092-9

51. Tachi Y, Yotsuji K (2014) Diffusion and sorption of Cs +, $\mathrm{Na}+$, I- and HTO in compacted sodium montmorillonite as a function of porewater salinity: integrated sorption and diffusion model. Geochim Cosmochim Acta 132:75-93. https://doi.org/10. 1016/j.gca.2014.02.004

52. Thyagaraj T, Salini U (2015) Effect of pore fluid osmotic suction on matric and total suctions of compacted clay. Géotechnique 65(11):952-960

53. Villar MV, Sanchez M, Gens A (2008) Behaviour of a bentonite barrier in the laboratory: experimental results up to 8 years and numerical simulation. Phys Chem Earth 33:S476-S485. https:// doi.org/10.1016/j.pce.2008.10.055

54. Wersin P, Kiczka M, Koskinen K (2016) Porewater chemistry in compacted bentonite: application to the engineered buffer barrier at the Olkiluoto site. Appl Geochem 74:165-175. https://doi.org/ 10.1016/j.apgeochem.2016.09.010

55. Xie M, Agus SS, Schanz T, Kolditz O (2004) An upscaling method and a numerical analysis of swelling/shrinking processes in a compacted bentonite/sand mixture. Int J Numer Anal Meth Geomech 28(15):1479-1502. https://doi.org/10.1002/nag.396

Publisher's Note Springer Nature remains neutral with regard to jurisdictional claims in published maps and institutional affiliations. 